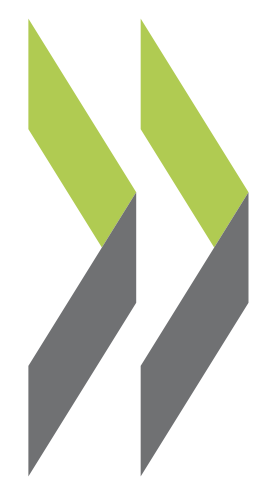

OECD Development Co-operation Working Papers No. 17

A Calculated Risk: How Donors Should Engage with Risk Financing and Transfer Lydia Poole Mechanisms 


\section{A Calculated Risk How Donors Should Engage with Risk Financing and Transfer Mechanisms}

Lydia Poole

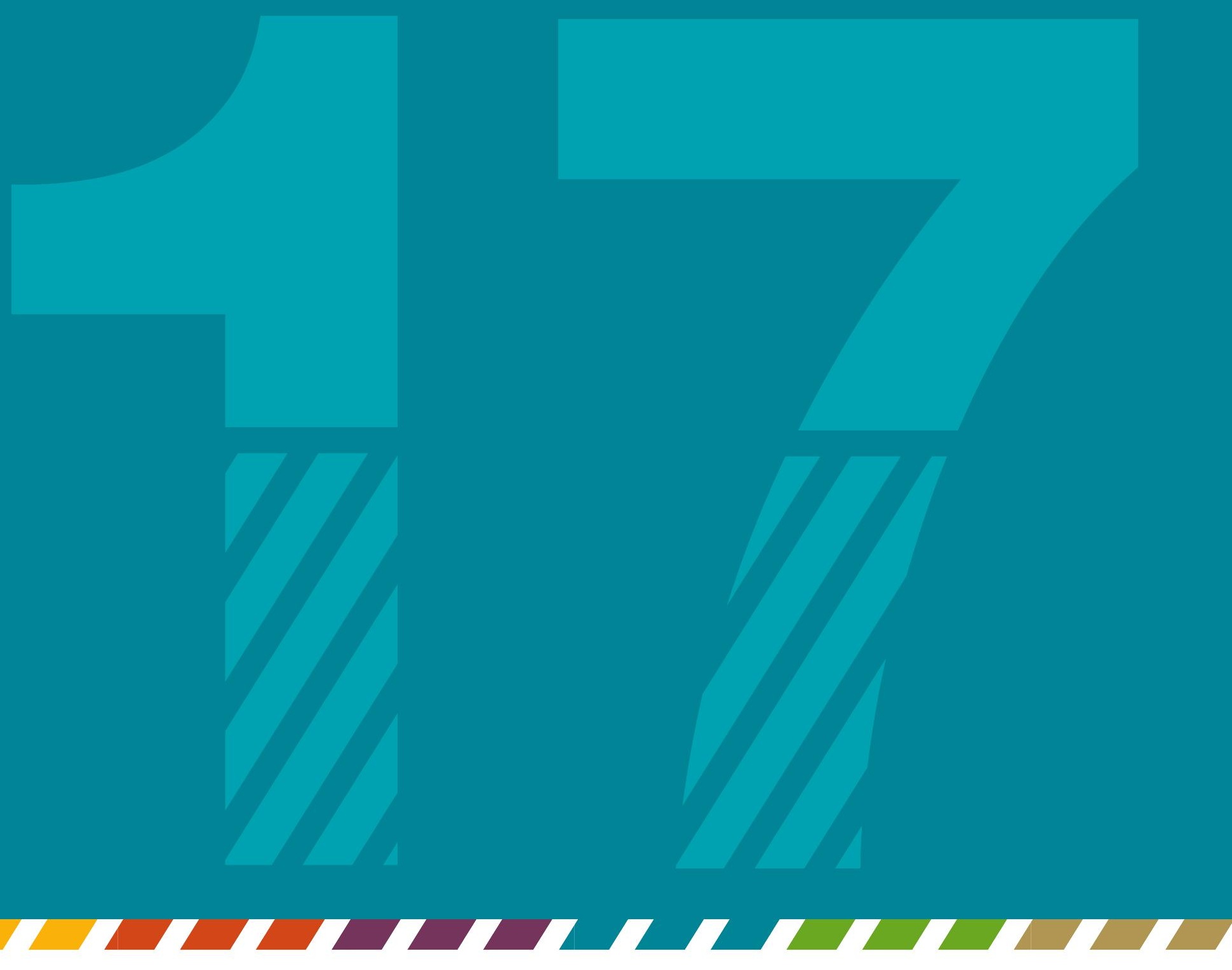

OECD DEVELOPMENT CO-OPERATION WORKING PAPER 17

Authorised for publication by Jon Lomoy, Director, Development Co-operation Directorate 


\title{
A calculated risk: How donors should engage with risk financing and transfer mechanisms
}

\author{
Lydia Poole ${ }^{1}$
}

\section{Abstract}

Better financial preparedness against risk is a central part of a comprehensive approach to disaster management. Risk financing and risk transfer are approaches to planning for risks that cannot be reduced or avoided practically or cost-effectively and may include a strategy and practical measures to ensure the availability of funds for post-disaster relief and reconstruction, commensurate with the scale and frequency of anticipated risks.

Risk financing is of growing interest to a wide range of development and humanitarian actors searching for solutions to bridge a growing global post-disaster financing gap.

This report describes key features of risk financing and risk transfer, examines some of the current challenges at the contextual and programmatic levels as well as institutional challenges donors might face in engaging in risk financing and recommends a set of principles and policy approaches to guide future donor support and engagement.

OECD Working Papers should not be reported as representing the official views of the OECD or of its member countries. The opinions expressed and arguments employed are those of the authors.

OECD Working Papers describe preliminary results or research in progress by the author(s) and are published to stimulate discussion on a broad range of issues on which the OECD works. Comments on the present Working Paper are welcomed and may be sent to dac.contact@oecd.org - the Development Co-operation Directorate, OECD, 2 rue André-Pascal, 75775 Paris Cedex 16, France.

This document and any map included herein are without prejudice to the status of or sovereignty over any territory, to the delimitation of international frontiers and boundaries and to the name of any territory, city or area.

\footnotetext{
${ }^{1}$ Lydia Poole (lydiapooleconsulting@gmail.com) is an independent consultant specialising in financing for risk and response to crisis. The ideas expressed in this paper are those of the author and do not represent the views of the OECD, the OECD's Development Assistance Committee (DAC), or their member countries. The author would like to thank Fergus McBean of the UK Department for International Development, Florian Neutze of the German Federal Ministry for Economic Cooperation and Development, Jaap Smit of the Netherlands Ministry of Foreign Affairs, Charlotte Benson of the Asian Development Bank and Richard Choularton of the UN World Food Programme, for excellent comments on an earlier draft of this paper and to the many individuals who participated in interviews. The author would also like to thank Rachel Scott, Senior Advisor at the Development Co-operation Division of the OECD, for facilitating the research for this paper, and to Stephanie Coic who prepared the paper for publication.
} 


\section{Executive Summary}

Risk financing involves the retention of risks combined with the adoption of an explicit financing strategy to ensure that adequate funds are available to meet financial needs should a disaster occur. Such financing can be established internally through the accumulation of funds set aside for future use or obtained externally through prearranged credit facilities. The banking sector, capital markets and international lending institutions are sources of risk financing. (OECD, 2012)

Risk transfer involves the shifting of risks to others who, in exchange for a premium, provide compensation when a disaster occurs, ensuring that any financing gap that might emerge is partially or fully bridged. Risk transfer may be obtained through insurance policies or capital market instruments such as catastrophe bonds. The insurance and reinsurance sectors are the main sources of risk transfer, although capital markets provide an alternative source. The payouts of risk-transfer instruments may be quantified on the basis of actual losses sustained by the protection buyer (indemnity-based), or the amount of such payment may be agreed upon by the parties irrespectively of actual losses and triggered by a physical parameter measuring the intensity of the hazard at given locations (parametric) or by an index comprising multiple measurements of such parameters for each event (parametric index). (OECD, 2012)

Risk financing is a critical element of a resilient future. The potential gains from risk financing as part of a comprehensive approach to risk management are wide ranging and include reduced humanitarian, fiscal and economic impacts, the creation of incentives to further reduce risk and greater confidence to invest with the potential to stimulate economic growth and poverty reduction.

Risk financing is part of the solution to managing risk more effectively, but it does not work always and everywhere. Risk-financing and risk-transfer mechanisms have limited applicability and uncertain outcomes, indicating the need for a cautious and multi-layered approach. There are a variety of risks and contexts - particularly conflict-affected and fragile states - where the existing suite of risk-financing and risk-transfer tools do not apply, and where demand for humanitarian and development actors to underwrite the cost of responding to crises will continue. Therefore, donors should be alert to the potential limits of risk financing. They should hedge their bets by pursuing investments in risk financing, a strategy which could provide long-term returns, while continuing to invest in approaches that have more reliable outcomes for at-risk populations in the short term. These other approaches include investing in social safety nets, emergency preparedness, a more riskinformed approach to humanitarian response, and by investing in complementary risk reduction measures.

Donors have an important role to play in improving risk-informed financial preparedness but will need to adapt a new modus operandi. Donors will need to put in place policies that establish risk financing as a corporate priority and to develop new approaches and modes of programming. Donor support to risk financing and risk transfer should take into consideration the following:

1. Comparative advantage. Donors should understand, play to, and refine existing comparative advantages. There is a sliding scale of engagement and investment options that donors may select, according to their resources, risk-taking culture, capacity and interest. Donors may want to engage in one or a combination of modes or levels of engagement. In addition, donors may need to adapt internal ways of working to accommodate new partnerships and programming approaches; invest in developing internal 
capacity; and develop ways of coordinating and collaborating across disparate internal technical teams.

\section{Potential levels of donor investment and engagement}

in risk financing and risk transfer mechanisms
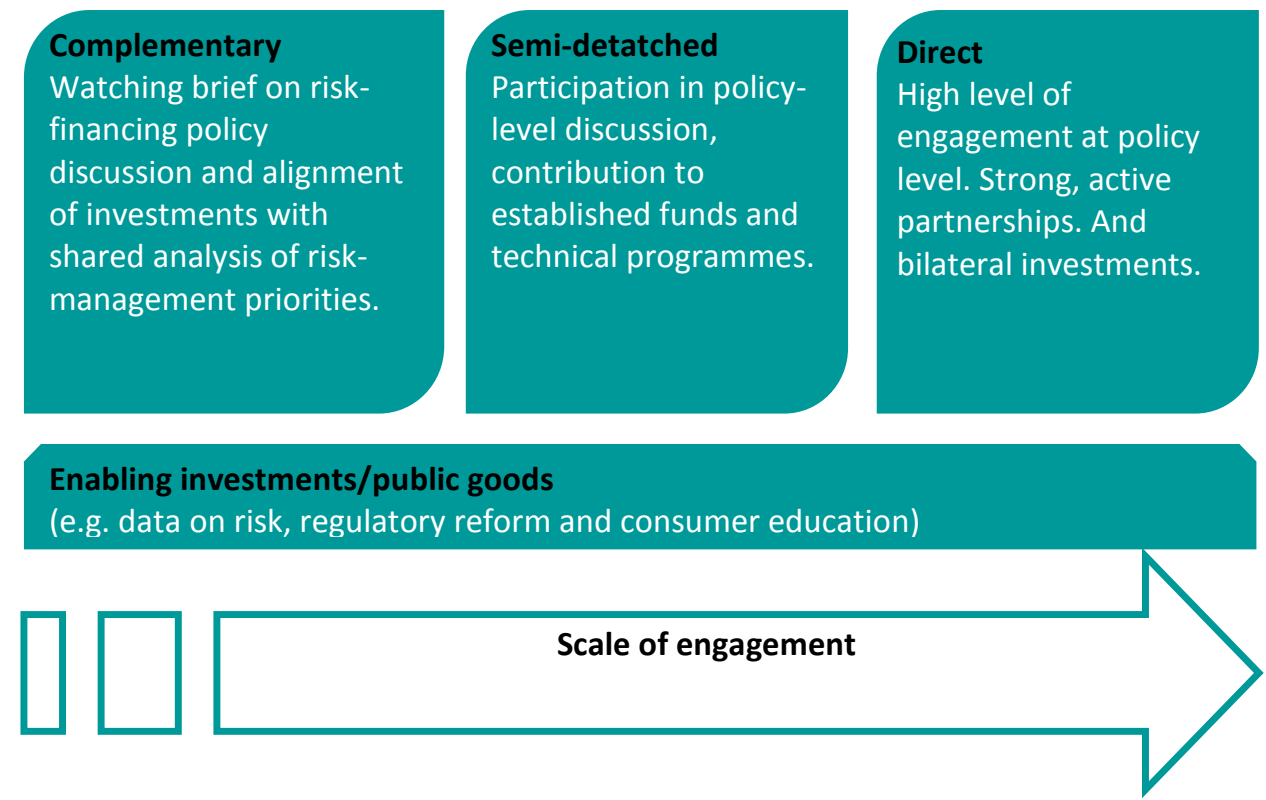

2. Catalytic investment. New technology, products, approaches and partnerships will be needed to address existing challenges in affordability and coverage, and to adapt to emergent risks. Donors have an important role to play in risk financing as 'first movers', providing catalytic investments in new approaches and markets where private sector actors might not otherwise engage. Donors should also underwrite the costs of a wider range of 'enabling investments' or 'public goods', including generating and sharing of risk data and providing support to markets, such as technical capacity-building, regulatory reform, consumer education and protection. These investments support the development of sustainable pro-poor, risk-financing and risk-transfer solutions in developing countries.

3. Collective approaches. Effective management of risk is the work of many actors across the public and private sector and civil society. Donors can play an important role as matchmakers and facilitators, creating opportunities and incentives for public, private and civil society actors to connect and develop partnerships. Donors can also influence incentives and create opportunities for actors to connect and work more effectively towards collective approaches to managing risk - including creating incentives for their partners to develop a shared analysis of risk, which underpins coordinated and comprehensive approaches to managing risk.

4. Complexity. Risk financing may be a worthwhile long-term investment but the process is unlikely to be straightforward. Accepting complexity and uncertainty comes with the territory. Donors should be realistic in their expectations and should accept: longer-term financial commitments; a potentially high failure rate and long-range returns on investments; complex and challenging chains of accountability and difficulties attributing results within the lifetime of donor planning cycles; and they will need to create or work in a culture that is able to learn and adapt. 
5. Caution. Risk financing and risk transfer are not without potential risks and unintended consequences. Donors should be alert to the potential limits and draw-backs of risk financing and be prepared to develop their own 'layered' approaches; rethink and adapt; and maintain complementary investments in approaches that have more reliable outcomes for at-risk populations in the short-term, such as social safety nets and humanitarian cash transfer programmes as well as disaster risk reduction. Donors should influence their partners and advocate in networks to ensure that products and initiatives take into account not just technical feasibility, client requirements and profit returns but also include the needs of the most vulnerable. 


\section{Introduction}

The financial cost of risk is increasing and the gap in resources to meet post-crisis relief, recovery and reconstruction needs is expanding. Global disaster losses and damages are growing as a consequence of increased exposure (such as population growth and density, urbanisation, poverty, industrial growth and environmental degradation) combined with increased frequency of hydro-meteorological extreme events and slow onset changes associated with climate change. These risks intersect with global risks including volatility in commodity prices, the risk of pandemic disease, as well as localised and regional political instability and conflict.

Unplanned, ex-post financing is an increasingly inadequate response to growing risk. In many developing countries governments, businesses and individuals have limited measures in place to secure financing for crisis response, recovery and reconstruction and often mobilise funds after a crisis event through budget reallocation, distress sales of assets, international aid and loans. Such ex-post funding is unpredictable and may not be timely or sufficient to meet relief, recovery and reconstruction needs. Failure to make adequate financial provisions against risk therefore may not only bear heavy costs for the individuals who may face impoverishment but also for governments, which may face acute fiscal crises, loss of public confidence and longer term economic consequences.

Better financial preparedness against risk is a central part of a comprehensive approach to disaster management. Risk financing and risk transfer involves putting in place a strategy to ensure the availability of funds for post-disaster relief and reconstruction, commensurate with the scale and frequency of anticipated risks. This strategy should exist within a comprehensive approach to disaster risk management which also considers how to reduce, mitigate and make practical preparations for residual risk. Technological innovations in measuring and modelling risk and in payment distribution systems, as well as the development of innovative, market-mediated risk-transfer products, mean that risk-financing and risk-transfer mechanisms are becoming increasingly possible in some developing country contexts, where they might once have been unthinkable.

Risk financing is a policy area increasingly noted as of interest for a wide range of development and humanitarian actors searching for solutions to bridge a growing global post-disaster financing gap. Risk financing is high on the political agendas of many OECD governments.

Relatively few OECD donors are actively involved in risk financing and those that are often feel that their engagement is still in its 'early days". Donors have an important role to play in advancing risk financing and risk transfer in developing countries, including financing technical assistance and public goods and helping to subsidise the development and start-up costs of market-mediated risk-transfer mechanisms. However, risk financing is not an easy option and donors will need to deepen their understanding and capacities in order to target their financial support and influence. 
This report was commissioned by the OECD under the direction of the OECD-led Experts Group on Risk and Resilience, and follows a recommendation for further investigation of opportunities for donors to support alternative risk-financing and risk-transfer mechanisms made in the OECD's Working Paper Risk and Resilience: From Good Idea to Good Practice (Mitchell, 2013).

This report:

- describes key features of risk financing and risk transfer, including outlining riskfinancing and risk-transfer mechanisms available at macro-, meso- and micro-social and economic levels (Chapter 2)

- examines some of the current challenges at the contextual and programmatic levels as well as institutional challenges donors might face in engaging in risk financing (Chapter 3)

- recommends a set of principles and policy approaches to guide future donor support and engagement (Chapter 4)

\section{NOTES}

\footnotetext{
${ }^{1}$ Donors with significant involvement in funding risk financing and risk transfer include the European Commission, Germany, Japan, the Netherlands, New Zealand, Switzerland, the United Kingdom and the United States.
} 


\section{What is risk financing and why does it matter?}

Risk financing in developing countries has been in an experimental phase since the early 2000s, drafting in new technologies and expertise from a range of actors to develop and test new products. Demand and political buy-in are gathering momentum and risk financing is increasingly noted as an area of interest for a growing range of development and humanitarian actors.

This chapter examines the theory and levels of support at the global policy level for risk financing as part of a wider risk management strategy in developing countries - and reviews some of the most prominent examples of donor supported programming contributing to risk financing and risk transfer at the micro-, meso- and macro- levels in developing countries.

\subsection{Risk financing in theory}

Risk financing represents an approach to planning for risks that cannot be reduced or avoided practically or cost-effectively. Risk financing and risk transfer should exist within a comprehensive approach to managing risk that comprises:

- risk assessment

- risk reduction, prevention, and mitigation measures, and

- emergency preparedness, including financial preparedness.

Risk financing is characterised by a shift from ex-post to ex-ante mobilisation of financing. Ex-post funding is typically untimely, unpredictable and insufficient, and carries unacceptable humanitarian and economic consequences. ${ }^{1,2}$ More timely, post-crisis financing on the other hand has the potential to protect lives and livelihoods, reduce human suffering, reduce economic impacts and often has a lower overall financial cost. Risk financing attempts to shift the mobilisation of funds away from ad hoc efforts in the wake of a crisis, towards a risk-informed strategy to secure access to funds in advance of crisis events.

Risk financing also has additional indirect benefits, potentially enabling economic growth and poverty reduction as well as incentivising risk reduction. Having measures in place to smooth the financial impact of risk should enable a shift away from coping mechanisms that impact negatively on longer-term economic prospects including reducing consumption, taking children out of school, asset sales, taking on high levels of debt and pursuing conservative economic strategies - such as, for example, growing a variety of lowyielding crops to spread risk. Having risk-financing measures in place may also give lenders and investors greater confidence that there is some form of insurance protecting their capital. Greater awareness of risk produced through the risk assessment process, and through the pricing of risk in insurance products, also creates a strong incentive for individuals, businesses and institutions to voluntarily reduce their exposure to risk. The incentive to reduce the cost of insurance premiums by voluntarily reducing exposure to risk is particularly compelling and insurance can therefore contribute to a positive risk-reducing feedback loop. 
Box 2.1: Key definitions

Risk The combination of the probability of an event and its negative consequences. (UNISDR ${ }^{3}, 2007$ )
Risk management. The systematic approach and practice of managing uncertainty to minismise
potential harm and loss. Risk management comprises risk assessment and analysis, and the
implementation of strategies and specific actions to control, reduce and transfer risks. (UNISDR,
2009)

Risk financing involves the retention of risks combined with the adoption of an explicit financing strategy to ensure that adequate funds are available to meet financial needs should a disaster occur. Such financing can be established internally through the accumulation of funds set aside for future use or obtained externally through prearranged credit facilities. The banking sector, capital markets and international lending institutions are sources of risk financing. (OECD, 2012)

Risk transfer involves the shifting of risks to others who, in exchange for a premium, provide compensation when a disaster occurs, ensuring that any financing gap that might emerge is partially or fully bridged. Risk transfer may be obtained through insurance policies or capital market instruments such as catastrophe bonds. The insurance and reinsurance sectors are the main sources of risk transfer, although capital markets provide an alternative source. The payouts of risk-transfer instruments may be quantified on the basis of actual losses sustained by the protection buyer (indemnity-based), or the amount of such payment may be agreed upon by the parties irrespectively of actual losses and triggered by a physical parameter measuring the intensity of the hazard at given locations (parametric) or by an index comprising multiple measurements of such parameters for each event (parametric index). (OECD, 2012)

Extensive risk. The widespread risk associated with the exposure of dispersed populations to repeated or persistent hazard conditions of low or moderate intensity, often of a highly localised nature, which can lead to debilitating cumulative disaster impacts. Extensive risk is mainly a characteristic of rural areas and urban margins where communities are exposed and vulnerable to recurring localised floods, landslides storms or drought. Extensive risk is often associated with poverty, urbanization and environmental degradation. (UNISDR, 2009)

Residual risk. The risk that remains in unmanaged form, even when effective disaster risk reduction measures are in place, and for which emergency response and recovery capacities must be maintained. (UNISDR, 2009)

Current policy indicates that risk financing should include a redistribution of risk across a 'layered' set of financing options (figure 2.1). Financial preparedness against risk typically starts with the assessment of risk exposure, and identification of potential financial liabilities. This is followed by a cost-benefit analysis of different financing options. On the basis of this analysis, a 'layered' financing strategy may be devised. Governments, for example, could create reserves and contingency budgets for frequent low-impact risks, and use budget reallocations and contingent credit arrangements for intermediate level risks. For infrequent, high-impact risks, where it may not be feasible to retain sufficient reserves, it may make sense to transfer the risk to insurance, reinsurance and private capital markets, effectively smoothing the cost of risk over time. Mexico's experience with layered approaches to risk financing is outlined in Box 2.2.

Risk financing is not just about insurance however. Risk transfer is an important tool within the risk-financing tool box but it is not the right tool for every circumstance. ${ }^{4}$ Insurance and transfer of risk to capital markets are costly and therefore typically appropriate only for the highest levels of risk and where the ability to withstand financial shocks is low. Without corresponding investments and behaviour changes that reduce exposure to risk, insurance may not be cost effective in some instances. 
Figure 2.1: Risk layering and the application of financial instruments

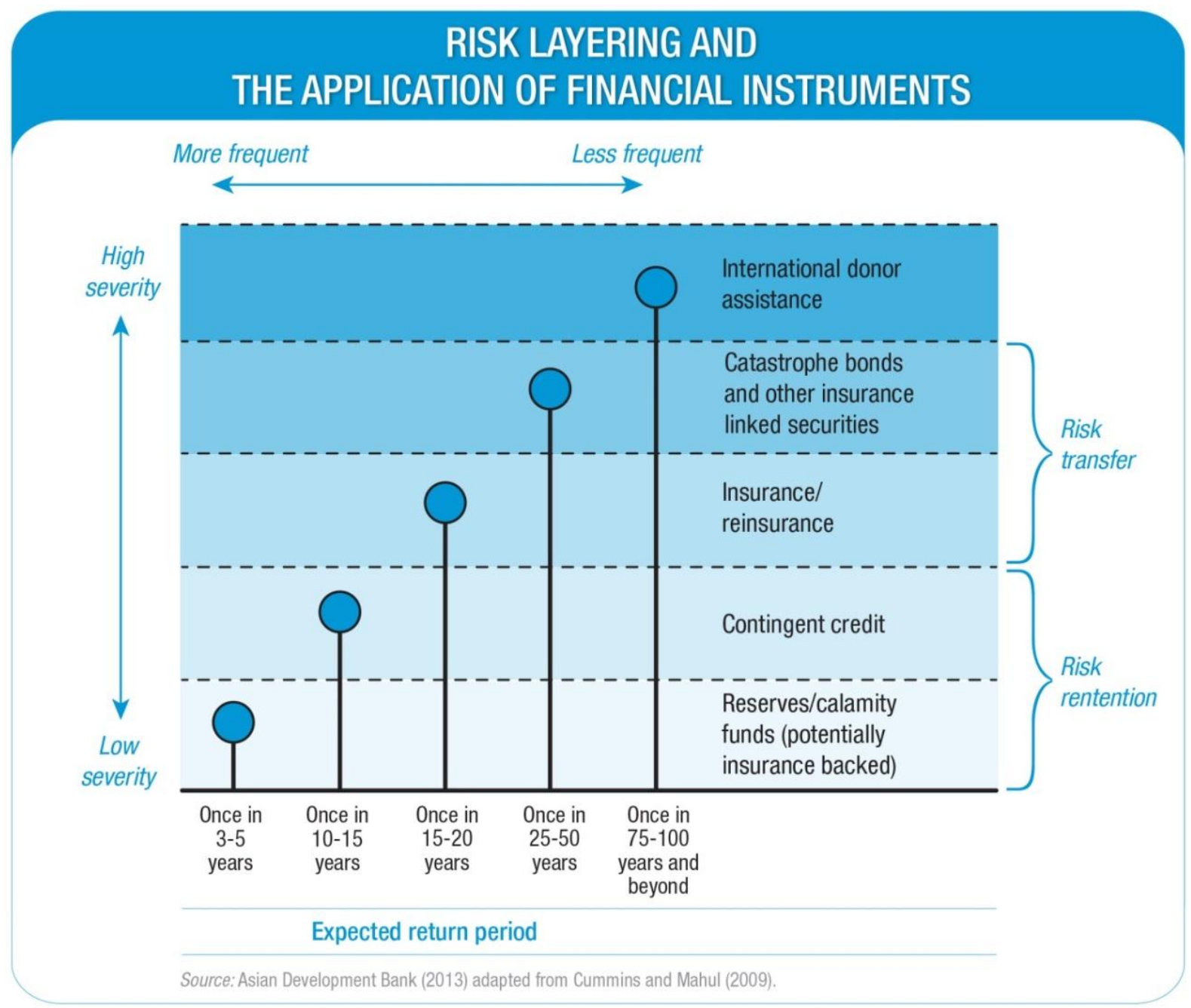




\section{Box 2.2: Mexico's layered approach to risk financing}

Mexico has progressively shifted towards an ex-ante approach to preparedness for natural disasters since the mid-1990s, including developing a legislative and institutional framework, investing in risk reduction and promoting a culture of prevention and insurance.

Ex-ante financing mechanisms. In 1996 the government of Mexico created the Natural Disaster Fund (Fondo Nacional de Desastres Naturales), known as FONDEN, to receive and allocate funds for post-disaster response - including rehabilitation of public infrastructure and low-income housingwithout disrupting planned budgetary expenditures. FONDEN uses budgetary resources (up to around USD 1 billion) to meet needs arising from more frequent disasters and negotiates marketmediated, risk-transfer mechanisms to meet needs arising from less frequent and higher-impact events. FONDEN includes windows for immediate post-disaster response and for prevention through the FOPREDEN (Program for Prevention) sub-account. In 2011 an additional Reconstruction Fund was created on a pilot basis to channel funds to state-level governments.

Ex-ante risk-transfer mechanisms. In addition to its USD 1 billion budgetary resources, FONDEN negotiates USD 400 million of indemnity-based insurance coverage and, in 2006, issued the world's first parametric government catastrophe bond. Now in its third issuance, the bond includes insurance coverage of up to some USD 300 million against low-frequency, high-impact earthquake and hurricane risk.

Policy commitment. Risk management is a policy priority for the Mexican government and is integrated throughout national planning processes. The government has also invested in building the capacity of national and local institutions to assess and reduce risk and to prepare for disasters.

Legal framework. In 2006 a new Federal Budget Law was enacted that required the Ministry of Finance and Public Credit to commit a fixed percentage of its annual budget to FONDEN and the Agricultural Fund for Natural Disasters (Componente de Atencion a Desatres Naturales or CADENA). This allocation, together with funds carried over from the previous year, must be not less than $0.4 \%$ of the Federal budget (typically around USD 800 million). If these sums are insufficient to meet needs, the law also stipulates that additional funds must be transferred from other budgets and reserves, including the oil revenue surplus.

Access to insurance. The Mexican government established weather index insurance coverage for small-scale farmers. Farmers with holdings of less than 20 acres are automatically enrolled in the scheme that sees premiums purchased by federal and state governments and payouts provided if rainfall drops below established thresholds.

Source: Based on Fuchs and Wolff (2011) and World Bank (2012).

Risk financing is increasingly technically feasible in developing countries. Advances in technology and the design of insurance products now mean that even where historic loss and hazard data are missing, low cost mobile weather stations and satellite data can collect and remotely transmit risk data. This information may be measured against indexes of anticipated losses to trigger insurance payouts. The use of these parametric indexes also circumvents the need for costly onsite verification of losses, dramatically cutting the cost of premiums and making insurance affordable for low-income individuals (Box 2.3). The expansion of distribution channels, including private sector microfinance providers, cooperatives and mobile money transfer services as well as the expansion of state-sponsored social safety net schemes, also means it is increasingly possible to target and direct payments in some contexts. 


\section{Box 2.3: Parametric index insurance}

Parametric indexes enable pre-defined payments that are based on expected losses, correlated against a measurable parameter (such as rainfall, temperature or earthquake intensity) or index of parameters. Traditional indemnity insurance relies on costly verification of actual losses whereas parametric insurance allows payments to be triggered automatically when pre-agreed risk thresholds are breached. Dispensing with the need for verification allows substantial savings to the insurer. These savings are reflected in reduced premium costs, making parametric insurance a more affordable product for low-income purchasers.

The prior agreement of payments and trigger thresholds, combined with independent measurement of data, also allows for much more rapid disbursement of payouts and reduces the risk of moral hazard.

Parametric indexes have been used widely in micro-insurance products such as the Kilimo Salama Agriculture Index Insurance in Kenya and MiCRO micro-catastrophe insurance in Haiti. Recent innovations include payments triggered in advance of expected losses based on modelled expected climatic conditions such as the Extreme El Niño Insurance Product in Peru.

Parametric indexes have also been used as the trigger for catastrophe bond payouts and are used to trigger access to the International Development Bank (IDB)'s contingent credit facility, avoiding the potential for moral hazard when disaster declarations are used as triggers.

Parametric indexes have also been developed to trigger payouts through regional risk pools such as the Caribbean Catastrophe Caribbean Catastrophe Risk Insurance Facility (CCRIF); the Pacific Catastrophe Risk Assessment and Financing Initiative (PCRAFI); and the African Risk Capacity (ARC)

One notable draw-back compared with traditional loss assessment is the increased likelihood of 'basis-risk', which is a disparity between actual losses and losses calculated by the index such that people who might have been seriously affected might not receive a payout and vice versa.

There is a convergence of interests across the public and private sector. The global insurance industry is increasingly interested in working in partnership with international actors to extend insurance products to developing countries, especially where this might otherwise have been considered unprofitable and excessively risky. Governments and lowincome individuals are seen by a growing number of global reinsurers as middle-income clients of the future and early engagement in these markets has become a long-term business strategy. ${ }^{5}$

The prospect of leveraging the resources and technical expertise of the private sector in building resilience is appealing to donors and affected governments alike. For example, the development of agricultural index insurance and sovereign risk-financing are noted as priorities for public-private sector action under the 2012 New Alliance for Food Security and Nutrition, and are being closely observed by many development policy makers. ${ }^{6}$ The Political Champions Group for Disaster Resilience identified co-operation with the private sector as a priority in 2012, with the United Kingdom proposing targeted support to the insurance industry. The Political Champions launched a new initiative in 2013 to jointly target the scaling up of market-mediated risk insurance in several low-income case study countries. ${ }^{7}$

Political commitments and demand are growing. Risk financing is recognised as a priority in the Hyogo Framework for Action 2005-2015 and there have been further highlevel political affirmations of the importance of risk financing have in the last three years.

For example, risk financing was identified as a priority of Mexico's presidency of the G20 in 2012. This led to high-level statements of commitment from G20 members and a joint publication that marshalled the experiences of 15 governments and focused on improving the assessment of disaster risk and strengthening financial resilience. The G20 and OECD produced a joint methodological framework on disaster risk assessment and risk financing in 
2012. Later that year the Sendai Dialogue reaffirmed the importance of financial protection against risk (World Bank, 2012a). The Global Assessment Report on Disaster Risk Reduction 2013 (UNISDR, 2013) and World Development Report 2014 (World Bank, 2013a) also highlighted the importance of risk financing and risk transfer to sustainable development.

Demand for technical assistance to develop sovereign risk-financing strategies and tools has gathered momentum as governments become more familiar with the potential benefits and observe functioning examples among their peers. The technical services of multilateral development banks are in particularly high demand.

\subsection{Risk financing in practice at the micro level}

The ability of individuals and households to make financial provision against risk depends on access to information about risk, access to markets providing appropriate and affordable financial services and insurance products, and to the existence of government-backed safety-nets against risks that exceed people's coping capacity. Individuals and households also require the financial capacity to save, borrow and purchase insurance - together with a sufficient understanding of these products in order to make informed choices.

Access to financial services for the poor is increasing. Access to affordable financial services provides people with the opportunity to save and borrow. Banking infrastructure also increases the possibility of directing payments from third parties including insurers, social protection schemes, remittances and informal loans or transfers within families and social networks. Many governments and multilateral institutions have developed a strong policy emphasis on increasing access to financial services for the poor. ${ }^{8}$

The reach and cost effectiveness of mobile money in particular may provide opportunities for poor households in remote and underdeveloped financial markets to manage risk. The ability to send money relatively cheaply via the M-PESA mobile money system in Kenya, for example, has contributed to an increased amount and volume of remittances. This has enabled some households to better absorb negative income shocks. Families without $\mathrm{M}$ PESA experienced a $7 \%$ fall in consumption after a major shock (Jack and Suri in Cull, Ehrbeck \& Holle, 2014).

Innovations in product design and technology over the last 10-15 years have pioneered new approaches to micro-insurance. The penetration of insurance in most developing countries is extremely low. Insurance markets are under-developed and they face a range of challenges in creating and marketing affordable products. Micro-insurance includes a range of insurance products specifically designed for low-income clients, protecting against risks such as accident, illness, death and natural disaster. Incorporating parametric indexes into insurance products targeted at low-income clients has dramatically reduced the cost of premiums, raising the possibility of extending insurance to the poorest and most risk-vulnerable communities.

Micro-insurance is often 'bundled' with other products and services including micro-credit, money-transfer services or social safety nets, which can greatly assist in accessing at-risk populations. Micro-insurance may also work in conjunction with government-run social safety nets by providing additional layers of protection and potentially reaching groups that are outside government-sponsored social protection and insurance schemes.

Micro-insurance is a growth industry for international development actors, particularly in the agriculture sector, as a means to foster economic growth among small-holder farmers and pastoralists. Over the last 10-15 years, there has been a mushrooming of global-level initiatives supporting innovation and learning in micro-insurance (Box 2.4). 


\section{Box 2.4: Global micro-insurance initiatives}

\section{The Microinsurance Network}

Initially established by donors, multilateral organisations and insurance professionals in 2002 as a working group of the Consultative Group to Assist the Poor (CGAP), the Microinsurance Network was formalised and launched in 2009 and registered as a not-for-profit in 2012. The network is a member association of micro-insurance experts and provides a platform for learning, coordination, generation and dissemination of knowledge and lessons on micro-insurance.

\section{www.microinsurancenetwork.org}

\section{Microinsurance Innovation Facility}

The Microinsurance Innovation Facility was established in 2008 with funding from the Bill \& Melinda Gates Foundation and additional funding from AusAID, Munich Re Foundation, United Nations Capital Development Fund (UNCDF)/United Nations Development Programme (UNDP) and the Z Zurich Foundation. The facility is managed by the International Labour Organization (ILO) and is an offshoot of the Microinsurance Network.

The facility supports innovation through providing grant funding to organisations to test new products models and strategies (it funded 63 organisations between 2008 and 2012); provides capacitybuilding support to organisations and individuals; provides research grants; promotes information and good practice exchange through its information products; and with A2ii and the UN Capital Development Fund (UNCDF), has supported market development in several countries.

\section{www.microinsurancefacility.org}

\section{Access to Insurance Initiative (A2ii)}

Established in 2009, the A2ii is the implementing partner of the International Association of Insurance Supervisors (IAIS) and is hosted by Deutsche Gesellschaft für Internationale Zusammenarbeit (GIZ) $\mathrm{GmbH}$. The A2ii's primary objective is to increase access to insurance in low-income countries through the promotion of effective regulation and supervision of insurance markets in ways that are consistent with international standards. A2ii is financed by the IAIS, CGAP, the German Federal Ministry for Economic Cooperation and Development (BMZ), the FinMark Trust, ILO and UNCDF.

\section{www.access-to-insurance.org}

\section{Global Index Insurance Facility (GIIF)}

Managed by the International Finance Corporation (IFC) and jointly implemented with the World Bank, the GIIF was established in 2009 as a multi-donor trust fund supported by the European Union, Japan and the Netherlands. Swiss Re is a major technical partner. The GIIF's objective is to expand the use of index insurance as a risk management tool in agriculture, food security and disaster risk reduction through: technical support to local insurers and finance institutions; technical support to governments to develop enabling legal and regulatory environments; feasibility studies and pilots; and premium subsidy to support the development of new insurance products.

\section{Index Insurance Innovation Initiative (14)}

14 was established in 2009 with funding from USAID (under the Feed the Future Initiative) and is a partnership with BASIS (hosted by the University of California Davis), the Food and Agriculture Organization (FAO) of the United Nations, the Micro-insurance Innovation Facility and Oxfam America.

14 supports a research agenda, testing and evaluating new approaches to design, outreach and education, appropriate risk layering and distribution channels to support 'a new generation of livelihood-optimised index insurance contracts'. 9 supports insurance pilots implemented through partnerships with researchers and private sector partners including local insurance companies, local financial institutions or non-governmental organisations (NGOs) and international reinsurers.

\section{http://basis.ucdavis.edu/i4-index-info/}


Social protection or social safety-nets are increasingly recognised as a key instrument in protecting individuals against shocks. Interest in social protection as a means of reducing poverty and protecting the poor against shocks grew in the wake of the global financial and economic crisis in 2008/9 and prompted, for example, the UN Chief Executives Board (CEB) to adopt the Social Protection Floor Initiative in 2009, promoting universal access to essential social transfers and services.

Current policy emphasis includes ensuring sustainable financing, increasing access for the most vulnerable groups and increasing the responsiveness of social protection systems to shocks (World Bank, 2012f and EC, 2012).

Social protection may be particularly important in extending financial risk management to poor and vulnerable individuals. Payouts do not need be tied to a specific type of risk and therefore may be particularly well suited to responding to extensive and everyday risks and cash transfers may be possible (including via international actors), even in fragile and conflict-affected contexts.

\subsection{Risk financing in practice at the meso level}

Risk financing does not yet systematically target meso-level actors as a priority. The current focus is primarily on mechanisms that benefit individuals and states, as well as supporting the development of domestic insurance markets more broadly.

Supporting the development of risk-transfer markets may indirectly benefit actors at the meso level. In some instances, risk insurance may target financial institutions and service providers that serve as 'aggregators' of risk, such as micro-insurance providers, and organisations assisting their members to manage risk such as co-operatives, unions, NGOs and self-help groups (Churchill and Matul (eds), 2012). For example, the Haitian microfinance institution, Fonzoke, with MercyCorps, DFID and others, formed the Microinsurance Catastrophic Risk Organization (MiCRO) with public and private sector partners in order to provide financial protection against risk to its clients using a parametric index-based insurance product. The index pays out against rainfall, wind speed and seismic activity and triggers payments to Fonkoze's loan clients. But it also provides cover to Fonkoze to cover basis risk, should the triggered payout be less than Fonkoze's actual losses (Microinsurance Innovation Facility, 2012).

Programmes targeting meso-level actors tend to be in middle and lower-middle income economies where risk transfer markets are more established. For example, the World Bank supports the Europa Reinsurance Facility (Europa Re), which includes activities to increase the level of catastrophe insurance penetration among homeowners, SMEs, and farmers, and reduce systemic risk to the insurance and banking in South East Europe. ${ }^{10}$ The Asian Development Bank (ADB) has also supported the development of an earthquake insurance facility in the Philippines, which targets medium-sized enterprise property owners (ADB, 2014).

Donors also underwrite political risk insurance for international investors in developing countries through their own development financing institutions and the Multilateral Investment Guarantee Agency (MIGA), which subsidises and facilitates political risk insurance for investors looking to do business in developing countries. Political risk insurance for investors is one of the few forms of risk insurance that provides protection against political instability and insecurity - though the direct benefits accrue to foreign-based companies rather than developing country actors. 


\title{
2.4 Risk financing in practice at the macro level
}

Governments bear the greatest responsibility for meeting the financial cost of risk and for regulating markets. Establishing risk-financing strategies and mechanisms in advance enables governments to increase their financial capacity to respond while protecting their long-term fiscal balances (World Bank, 2012c). Supporting the development of markets offering risk-financing and risk-transfer products for organisations and individuals enables a culture of greater voluntary risk management and could reduce the burden of sovereign financing liabilities. Supporting governments to develop their own risk-financing strategies and regulating markets providing private risk-financing and insurance products is therefore a logical and potentially high-yield investment.

Sovereign risk-financing is rapidly evolving field. Various mechanisms designed to increase the availability of risk-financing options for governments have been developed over the last 10 years, including access to contingent credit, regional sovereign risk pools and catastrophe bonds (Box 2.5).

\section{Box 2.5: Recently emerged sovereign-risk-financing tools}

\begin{abstract}
Contingent credit lines are pre-negotiated credit arrangements that can provide rapid access to funding at preferential rates to governments in the event of crises, including natural disasters and economic shocks. They are typically available to existing loan customers and eligibility may be contingent on demonstrating that effective disaster risk management planning and measures are in place.
\end{abstract}

Examples include: Japan International Cooperation Agency (JICA)'s Stand-by Emergency Credit for Urgent Recovery (SECURE); International Development Association (IDA)'s Immediate Response $\underline{\text { Mechanism and Crisis Response Window; and IDB's Contingent Credit Line. }}$

Catastrophe bonds are a method of transferring insurance risk to capital markets. Insurance and reinsurance companies, governments and corporations sell bonds on the private capital markets and investors receive an attractive return on their investment, typically over a three to four-year period, on the understanding that in event of a pre-defined crisis, part or all of their investment will be transferred to the insurance company to meet the cost of disaster losses. Payments may be calibrated against parametric triggers.

Examples include: Mexico's MultiCat catastrophe bond programme.

Sovereign risk pools pool resources to spread risk and negotiate preferential insurance and reinsurance rates. The pool may retain part of the funds derived from subscriptions, may progressively accumulate reserves, and transfer higher levels of risk to reinsurance and financial markets at more favourable rates than individual states could otherwise achieve. Several regional risk pools protecting against natural disaster risks and using parametric triggers have been established since 2007.

Examples include: the Caribbean Catastrophe Risk Insurance Facility (CCRIF); the $\underline{\text { Pacific }}$ Catastrophe Risk Assessment and Financing Initiative (PCRAFI); and the African Risk Capacity (ARC)

Governments need targeting and distribution infrastructure as well as liquidity. In addition to securing liquidity, complementary investments in targeting and distribution networks to channel payments in event of a crisis also need to be developed. Social protection schemes are a primary route for distribution of government transfers to individuals, and these may rely on, and be complemented by, payment systems developed by the private sector. As noted above, social protection has risen significantly as a policy priority among development donors and multilateral agencies and an increasing number of middle and in some cases low-income countries have established large-scale social protection programmes. ${ }^{11}$ 
Governments play a critical role in enabling and regulating markets. Encouraging and enabling individuals and organisations to put in place their own risk-financing strategies reduces governments' contingent liabilities. Financial education, consumer protection and market regulation are important pre-requisites for the development of sustainable markets in which poor people can safely access affordable and reliable financial products and services. Actors in the microfinance and micro-insurance sectors increasingly recognise the need to ensure effective regulation and market protection. ${ }^{12}$

Multilateral development banks have strong comparative advantages in advancing sovereign risk-financing. They often have long-term partnerships with their lending partners and established relationships with key influencing and decision-making elements of government, notably ministries of finance. Their programming typically spans multiple sectors so they are well positioned to support the integration of risk management. Crucially, multilateral development banks are also able to provide access to financing for risk reduction and post-disaster relief and reconstruction. They are also able to act as intermediaries for their clients in negotiating access to reinsurance and financial markets. The Asian Development Bank, the Inter-American Development Bank (IADB) and the World Bank are either in the process of substantially expanding their financing service offerings in risk financing and insurance or have done so already (Annex 1).

But it is not only multilateral development banks that operate in this sphere. In 2013 Japan established its own contingent credit line, SECURE, to provide immediate liquidity to partner countries eligible for Japanese official development assistance (ODA) loans following a disaster event. The credit arrangement is agreed in advance and activated on the basis of a mutually agreed soft trigger. The credit facility is typically complemented by technical support to develop disaster risk management capacity. The facility agreed its first loan in March 2014 to support post-disaster reconstruction following Typhoon Haiyan in the Philippines. ${ }^{13}$ 


\section{NOTES}

${ }^{1}$ Becerra, Cavallo and Noy, (2012) calculate that international aid surges cover just $3 \%$ of post disaster economic damages.

${ }^{2}$ Von Peter, von Dahlen, and Saxena (2012) estimate that "a typical (median) catastrophe causes a drop in growth of $0.6-1.0 \%$ on impact and results in a cumulative output loss of two to three times this magnitude, with higher estimates for larger (mean) catastrophes. Well insured catastrophes, by contrast, can be "inconsequential or positive for growth over the medium term as insurance payouts help fund reconstruction efforts."

${ }^{3}$ UNISDR definitions can be found at: http://www.unisdr.org/we/inform/terminology

${ }^{4}$ The allure of insurance as a solution to the growing risk-financing gap may be a powerful one. Tom Mitchell, Head of Climate Change, Environment and Forests, Overseas Development Institute, and Senior Advisor, Climate and Development Knowledge Network (CDKN) argues for example "At the moment insurance is simply too prominent, seen by too many governments and agencies as a first move rather than a later consideration." in Seduced by disaster insurance? Don't dive in a blog for the CDKN, 19 June 2012. http://cdkn.org/2012/06/seduced-by-disaster-insurance-dont-dive-in/

${ }^{5}$ Lloyds (2010) suggest for example that "Currently profits are modest, but there is the potential for significant returns in the future. And there are other benefits to the commercial insurer, ranging from developing innovative new policies to building a brand and client base in economies that have largely been untapped. Today's low income communities in China, India or Latin America could be tomorrow's affluent consumers."

${ }^{6}$ The New Alliance is an initiative comprising African governments, donors and private sector actors, agreed at the G8 Camp David Summit in 2012, which aims to "increase responsible domestic and foreign private investments in African agriculture, take innovations that can enhance agricultural productivity to scale, and reduce the risk borne by vulnerable economies and communities."

http://www.whitehouse.gov/the-press-office/2012/05/18/fact-sheet-g-8-action-food-security-andnutrition

${ }^{7}$ The expert-level group comprises the UK Department for International Deveopment (DFID), USAID, World Bank, ILO, GIZ, SECO, European Commission, Swiss Re, Munich Re, Willis and Allianz. The World Bank has completed market surveys to identify priority countries for engagement in 2014.

${ }^{8}$ For example, Cull, Ehrbeck \& Holle (2014) note that "The G20 made the topic one of its pillars at the 2009 Pittsburgh Summit. By fall 2013, more than 50 national-level policy-making and regulatory bodies had publicly committed to financial inclusion strategies for their countries. And the World Bank Group in October 2013 postulated the global goal of universal access to basic transaction services as an important milestone toward full financial inclusion."

${ }^{9}$ As described by BASIS http://basis.ucdavis.edu/i4-index-info/

${ }^{10}$ See

http://web.worldbank.org/WBSITE/EXTERNAL/TOPICS/EXTFINANCIALSECTOR/EXTDISASTER/0, contentMDK:23305437 menuPK:8921438 pagePK:64168445 piPK:64168309 theSitePK:8308421, $\underline{00 . h t m l}$

${ }^{11}$ For example, Asignación Universal por Hijo para Protección Social in Argentina; Bolsa Familia (and the new Brasil Sem Miséria) program in Brazil; Productive Safety Nets program in Ethiopia; Mahatma Gandhi National Rural Employment Guarantee program in India; Di bao reforms in China; Progresa and Oportunidades programs in Mexico. As noted in World Bank, $2012 \mathrm{f}$.

${ }^{12}$ Micro finance for example has experienced a series of problems following the shift from donor and NGO subsidised enterprises to fully for-profit models including in some instances very high rates of interest, enabling high levels of indebtedness among the very poor and the collapse of some micro finance institutions in "sub-prime-style "microfinance meltdowns". See for example Bateman and Chang, 2012. Many donors and policy actors involved in micro insurance consulted during research for this paper identified market regulation, consumer protection and education as major priorities. 
${ }^{13}$ Japan International Cooperation Agency (JICA) signed a loan agreement with the Government of the Republic of the Philippines to provide a 50-Billion Yen ODA loan on $19^{\text {th }}$ March 2014 http://www.jica.go.jp/english/news/press/2013/140319 03.html 


\section{What are the challenges?}

There are a number of important outstanding implementation challenges associated with risk financing and risk transfer in developing countries. Donors should also be alert to the fact that new challenges will continue to emerge. This chapter considers the following:

- contextual challenges- factors in the overall operating environment in partner countries that shape, and sometimes restrict, how donors can function

- programmatic challenges- factors that influence how development, climate change and humanitarian assistance programmes are designed and the results that can be achieved

- institutional challenges- structural factors that influence how donors, and their staff, behave and operate.

\subsection{Contextual challenges}

The list of practical challenges to achieving an ideal, typical, layered approach to risk financing are substantial, particularly in conflict-affected and fragile settings. A lack of knowledge and demand, limited infrastructure and 'missing markets' are significant barriers to the uptake and scale-up of risk financing and insurance. There are also numerous risks and a variety of contexts where the existing suite of risk-financing and risk-transfer tools do not apply and where demand for humanitarian and development actors to underwrite the cost of meeting needs through other means will continue.

There are many circumstances in which risk-financing and risk-transfer approaches are not currently applicable or appropriate. Many of the current suite of risk-financing and risk-transfer tools are distributed according to technical feasibility, demand and ability to pay, which in reality often does not correlate well with distributions of risk and vulnerability. In addition, there appears to be a broad spectrum of contexts and risks for which the current suite of risk-financing and risk-transfer tools do not apply.

The current focus of attention is almost exclusively on financial preparedness against natural disaster risks, with the notable exception of a small number of credit facilities and insurance products designed to alleviate the economic and fiscal impacts of volatility in commodity prices.

Risk-transfer products in particular address risks that can be quantified and modelled and do not always match the reality of exposure to multiple intersecting risks. Insurance products relying on parametric indexes often focus on one or two hazards - typically droughts, earthquakes or hurricanes. Parametric insurance products are not sufficiently sensitive to respond to highly localised risks or where multiple intersecting risks are present. Lower levels of risk, particularly slow onset and extensive risk, are typically too costly to address through risk transfer. There may be contexts in which climatic changes - such as rising sea levels and changes in temperature and precipitation - may be changing observable patterns of frequency and intensity of risk in unexpected ways and where risk financing and transfer may not be realistic approaches in the medium or long term.

Risk of political instability and conflict - including fraud and corruption - are typically considered too unpredictable and costly to insure, and extending insurance services into markets where rule of law and security are seriously compromised is not currently 
considered feasible or cost-effective from the perspective of many commercial insurers. The obvious exception is the case of investment guarantees where donor and international financing institutions underwrite political risk insurance.

The heavy emphasis on natural disasters also reflects in part the institutional segmentation of international engagement with risk, which has created a policy and technical community focused primarily on reducing natural disaster risk. The institutional configuration of international engagement with risk therefore represents a significant contextual challenge to achieving a more comprehensive approach to risk management (Box 3.1).

Box 3.1: Levels of risk management silos

1. The siloing of risk management from other aid programming, with a perception that risk management is a specific sector and a stand-alone strategic or programmatic objective rather than a transversal approach.

2. The siloing of general risk management approaches into separate initiatives on disaster risk reduction, climate change adaptation, social protection, natural resource or ecosystem management, conflict prevention, and the prevention of undernutrition.

3. The siloing of specific risk management approaches applied to individual hazards, with flooding and cyclones separated from geophysical hazards such as earthquakes and volcanoes, separated from landslides, separated from epidemics. These in turn are divorced from the less common initiatives to counter economic and geopolitical risk.

Source: Mitchell, 2013

Support for investing in risk financing at the political level is fundamental. Sovereign risk-financing is heavily dependent on political commitment from developing country governments, including a willingness to undertake legal and institutional reforms, and to allocate resources in support of risk financing. International support to sovereign riskfinancing is demand-led and, with the notable exception of the African Risk Capacity (ARC) risk pool, is currently primarily in demand among middle-income and some lower-middle income countries.

In order for insurance markets to flourish and extend their service offerings to at-risk groups, there is often a need to invest in enabling markets to function more efficiently - including through regulatory reform. This is particularly for the case of parametric insurance, which many legal frameworks do not yet recognise, and potentially also for premium subsidy. The willingness and capacity of governments to use public policy to support and influence the development of risk-transfer markets is extremely important in achieving scale and sustainability in risk-financing and risk-transfer solutions. For example, an estimated $60 \%$ of people covered by micro-insurance globally live in India, where the state has actively supported mass health insurance schemes and agriculture and livestock insurance (Churchill and Matul (eds), 2012).

Targeting and distribution infrastructure may need to be built simultaneously. The liquidity secured through sovereign risk-financing planning requires a pre-existing targeting and distribution infrastructure, such as a social protection mechanism, which may be underdeveloped or absent in many settings. Micro-insurance is typically bundled with other services (including access to credit and agricultural inputs), or may be grafted on to safety net programmes, which enhances their appeal to consumers and reduces the need to invest in a separate distribution network. If these are absent or under-developed however, substantial investments in targeting and distribution infrastructure and in enabling markets may need to be made alongside securing financing against risk, indicating the need for a high level of commitment and coordination across investments. 
Access to affordable and comprehensive data and information on risk is often lacking. Many developing countries lack historic data on hazards and losses and they may have limited infrastructure to capture, process and analyse data. Developing country governments often rely on the supply of data from meteorological, seismic and space agencies of OECD member governments, often on an informal pro bono basis. Risk data deficits pose huge challenges in identifying and prioritising risks and risk management measures, inhibit the development of market-based, risk-transfer solutions, which rely on probabilistic risk modelling in order to assign a cost to risk and set premiums accordingly, and limit the potential for voluntary risk reduction and self-protection based on an understanding of risk and exposure.

There is a clear need for increased and sustained investment in the production of data for risk analysis and enhanced sharing of data, through the agreement of data standards and open data commitments and platforms. The social and economic benefits of sharing risk data outweigh the financial or competitive gains which could accrue to data providers - so for not-for-profit data producers, there is a strong case for investing in and sharing data as a public good in order to facilitate risk-informed decision-making, innovation and adaptation. ${ }^{1}$

Political support for open data has gathered momentum within the disaster risk community and a growing number of initiatives and dialogues, such as the biennial Understanding Risk Forum, include both public and private sector actors and are promoting inter-operable and open data on risk. The World Bank and Global Facility For Disaster Reduction And Recovery (GRDRR)'s Open Data for Resilience Initiative (OpenDRI) for example has made more than 1,000 open risk datasets, developed open source software platforms and tools to enable local sharing and working with open data at local and national level, and published a field guide to managing and using open risk data (World Bank, 2014). The Africa Risk View (ARV), developed by WFP, has a wide range of potential applications for governments, development and humanitarian actors in addition to the role it plays in supporting the African Risk Capacity (ARC) risk pool (Box 3.2).

Indeed there are many current initiatives seeking to improve access to risk data - identifying which of these are likely to have the greatest transformative potential may be the greater challenge for donors.

\section{Box 3.2: Africa Risk View (ARV)}

ARV is a risk analysis tool which combines weather and crop data with data on vulnerable populations and historic analysis of the costs of response to generate information for decision-makers to anticipate emerging crises and initiate preparedness and early response to drought. ARV is able to provide estimates of the number and location of people likely to be affected by food insecurity and the probable maximum costs of drought-related responses before an agricultural season begins and as the season progresses for every first-level administrative unit in sub-Saharan Africa.

ARV is a core component of the ARC risk pool and operates as a parametric tool to trigger cash payouts from the pool for early response to emerging food security crises. Understanding the expected cost of response also assists members of the ARC to determine the level of cover they would like to purchase.

The existence of an objective and widely accepted early warning tool which both identifies and indicates the cost of risk could also be used to trigger early action from other stakeholders however and could be used to initiate assessments, preventive activities and to inform decisions to allocate financial resources, including donor funds, to early preventive measures.

Adapted from www.africanriskcapacity.org/africa-risk-view 


\subsection{Programmatic challenges}

Programmatic challenges are evolving as the field of risk financing matures and as implementers shift from a focus on the technical feat of developing viable risk-transfer tools towards bringing them to scale, making them affordable, ensuring they benefit those most at risk, and building comprehensive risk-financing approaches.

There is a lack of integration and complementarity across development-led and humanitarian-led programming. In contexts where the current suite of risk-financing tools do not apply, particularly in conflict-affected situations, humanitarian assistance will remain an important means to meet post-disaster needs. Humanitarian actors broadly acknowledge that a shift towards a more anticipatory and preventative approach to humanitarian crises is overdue (OCHA, 2014). Humanitarian actors are often external to the risk-financing debate and to broader risk management processes and discussions, yet they could benefit significantly from, and contribute to, emerging policy, risk analysis, and programming innovation, particularly for populations who are unlikely to benefit from mainstream riskfinancing and risk-transfer tools.

In practice, humanitarian actors have a consistent presence in many of the world's most protracted crises. Often they act as the delivery mechanisms for distribution of risk transfer and risk-financing resources, and indeed it is anticipated that the country plans submitted by African governments to the ARC risk pool will include humanitarian organisations as partners to target and deliver financing, particularly where government safety nets are not in place. Moreover, humanitarian and multi-mandate organisations have been central to some of the most innovative risk-transfer programming to emerge in recent years, including:

- WFP's role in developing ARV and their involvement in piloting and scaling up microinsurance, for example through theR4 Rural Resilience Initiative (R4), in partnership with Oxfam America

- Mercy Corp's partnership with Fonkoze in developing MiCRO in Haiti.

There may be a need to bring humanitarian actors up to speed with the fundamental principles and practical challenges of risk financing so that they can better understand what their direct contribution might be, and where there may be programming complementarity, particularly as they look to move towards more anticipatory and preventive approaches. For example, the analysis produced by ARV - the agro-climatic analytical platform designed to inform and trigger the ARC risk pool, including estimating food insecurity response costs could have multiple potential applications for humanitarian actors including providing an objective trigger for initiating early action in food security crises in Africa and informing analysis on the cost of humanitarian response. ${ }^{23}$

Achieving affordability and scale in micro-insurance is a major programming challenge. Many micro-insurance pilots have struggled to reach scale. Achieving an affordable product that provides value to the consumer is difficult, particularly in early stages of development, where investment costs to reduce basis risk may be high. It is difficult to achieve scale without bringing down the cost of premiums, yet it is difficult to reduce the cost without achieving a large, diversified pool of subscribers. Public policy tools, including premium subsidy, social insurance, input subsidy and licencing, may be necessary to incentivise and influence the development of accessible and quality insurance products (Clarke and Wren-Lewis, 2013).

The question of premium subsidy looms large over the micro-insurance debate. There is a risk that subsidy sends the wrong signals and creates disincentives for risk reduction. Donors are, therefore, understandably reluctant to set foot on the 'slippery slope' towards 
subsidy. But in order to reach scale and sustainability (including where insurable populations are small) and to reach the most vulnerable, there will be circumstances under which some form of subsidy will be necessary. ${ }^{4}$

There may be opportunities to develop alternative approaches or 'smart subsidies' to promote affordability, access and uptake of insurance - and promising examples of innovative approaches to incentivising insurance are emerging. These may benefit from increased investment and experimentation. In Ethiopia for example, the R4 Rural Resilience Initiative has developed an alternative mechanism to enable the poorest to access insurance by giving them the opportunity to pay for insurance premiums through their labour which in turn contributes to building individual and community assets that reduce disaster risk (Box 3.3). Mobile phone companies are teaming up with insurance companies to offer life insurance as a loyalty incentive or 'freemium' (where subscribers can supplement free insurance with additional premium contributions), particularly in sub-Saharan Africa and South Asia. Mobile companies benefit from a more competitive service offering, while insurance companies benefit from access to customers and payment systems (Pénicaud and Katakam, 2014). Trustco Mobile in Zimbabwe, for example, offered life insurance to its customers as a loyalty rewards in partnership with EcoLife and First MutualLife Insurance and attracted 1.6 million subscribers within a year (Churchill and Matul (eds), 2012).

In spite of some positive examples, we still do not know enough about what works and how or whether it benefits people at risk. Commitments to risk financing and risk transfer have been made largely on the basis of confidence in the theory and experiences in developed countries rather than on a sophisticated understanding of the costs and benefits or indeed impacts and potential transformative outcomes in middle and low income settings. This is understandable in an experimental period but understanding what works, for whom, and why, is much more important if programmes are to be implemented at scale.

Although the evidence base on the success of micro-insurance is rapidly growing - and focusing less on uptake and more on impact - it is still difficult to determine clear lessons for programme design from the diverse range of studies, institutions and platforms (Box 4).There may be a need in this particular case for greater streamlining and improved communication of emerging evidence and good practice.

The success of sovereign, disaster risk-financing has similarly emphasised the establishment of strategies and implementation of tools and mechanisms. Some donors have raised concerns about the cost effectiveness and impact of sovereign, marketmediated transfer mechanisms. ${ }^{5}$ Notably, the World Bank and Global Fund for Disaster Risk Reduction and Recovery (GFDRR) supported by the UK Department for International Development (DFID) are currently undertaking a large multi-year research project to develop a tool to enable decision-makers to better identify when risk-financing and risk-transfer approaches are likely to be appropriate and effective. ${ }^{6}$

There may be downside risks and unintended consequences. There is typically little preexisting demand for insurance in developing countries and with low levels of financial literacy potential clients may have limited capacity to critically evaluate products. International development actors should be sure they are confident that the product they are subsidising has real value for poor people and cash-strapped governments, given the opportunity costs involved in purchasing insurance and credit. 


\section{Box 3.3: The R4 Rural Resilience Initiative (R4) - increasing access to insurance through innovation and smart subsidy}

Oxfam America (OA) and the United Nations World Food Programme (WFP) launched the R4 Rural Resilience in 2011. R4 is an example of a creative and risk-taking programme developed outside of the policy mainstream, which has pioneered new practical solutions and approaches to achieve scale and enable access to risk financing for the poorest. R4 currently operates in Ethiopia and Senegal and is being scaled out to Malawi and Zambia.

In Ethiopia, R4 is jointly implemented by WFP, OA, the Relief Society of Tigray (REST), the Organisation for Relief and Development of Amhara (ORDA), and a range of public and private partners, including insurance companies and research institutions, such as the International Research Institute for Climate and Society at Columbia university (IRI).

R4 is a layered risk management programme for rural farmers, and includes a combination of risk management strategies including improved resource management (risk reduction), insurance (risk transfer), microcredit and livelihoods diversification (prudent risk taking) and savings (risk reserves).

In Ethiopia, the initiative is grafted onto the existing government-led Productive Safety Net Programme (PSNP) and uses PSNP's local infrastructure and targeting mechanisms to identify and access clients. In Senegal, R4 builds upon WFP's conditional transfer interventions. In the event of seasonal droughts client farmers receive automatic payouts calibrated against parametric index thresholds. The payouts enable farmers to repay loans, keep their children in school, and purchase seeds and inputs for the following season. They also help farmers avoid negative coping strategies such as selling of assets. Access to credit is provided through partnerships with micro-finance institutions.

The R4 initiative builds upon the success of HARITA (Horn of Africa Risk Transfer for Adaptation) in Ethiopia, a partnership established between OA and Swiss Re in 2007, with funding from The Rockefeller Foundation, Swiss Re and OA. At first, it was considered something of an exploratory venture. Contrary to policy orthodoxy at the time, the initiative targeted provision of insurance to poor households rather than service aggregators. The initiative also focused on achieving scale as quickly as possible rather than beginning with a small-scale pilot, which also proved somewhat controversial.

R4 has proved highly successful in achieving scale. From just 200 households in the initial roll-out in 2009 , over 25,000 households across 83 villages purchased insurance in 2014 . The initiative reached a major milestone in 2012 when more than 12,000 drought-affected households received an insurance pay-out of over USD 320,000. This is the first time that a weather index insurance programme in Ethiopia has delivered pay-outs at such a large scale directly to small farmers. In its first year of implementation in Senegal, after the piloting stage, R4 has reached almost 2,000 farmers with insurance coverage.

R4's major innovation is its 'insurance-for-work' (IFW) option. While better-off farmers purchase premiums with cash, the poorest farmers are offered work on risk-reduction focused public works in exchange for an insurance premium. Demand for insurance has proved high among both the poorest and better-off farmers: for example, in the initial pilot in 2009 , an uptake rate of $34 \%$ was recorded for cash-paying insurance schemes, which significantly exceeds most other micro-insurance products. The R4 'smart subsidy' option supports demand and a sustainable market for insurance without manipulating price or establishing dependence on long-term subsidy and crucially, enables the most vulnerable to benefit.

WFP, recognising the potential for index insurance and IFW as a means to enhance the resilience of rural livelihoods to recurrent shocks, initiated the process to mainstreaming them within its programmes globally, replicating and scaling up access to insurance alongside its food and cash for work programmes, in partnership with OA.

Sources: Oxfam America, 2014; World Bank, 2013b; and additional information provided by Oxfam America and WFP. 
The interests of the private sector, on one hand, and vulnerable populations and governments, on the other, may not always coincide. The experience of the microfinance industry indicates that when international actors with a commitment to poverty reduction are involved in developing and subsidising products, there may be a level of assurance that products will benefit the poor, but a shift towards a fully for-profit model in context with inadequate regulation and consumer protection may open the door to inappropriate and poor value products (Bateman and Chang, 2014).

Failure to scale up insurance pilots may damage public confidence and future demand for insurance. There is a risk that heavy reliance on international reinsurance in many donorfunded projects could crowd out the development of local insurance markets. As risks change and potentially increase in frequency and intensity, insurance may be withdrawn by the private sector leaving former clients exposed.

Risk-informed decision-making is limited by the lack of a shared analysis and inclusive dialogue around risk. Achieving a coherent, multi-hazard analysis, with a shared analysis of prioritised actions to reduce, transfer and prepare for risk behind which governments, donors and international actors could effectively mobilise and target their resources, is extremely difficult.

At country level there may in fact be many risk assessments but they are often overlapping, incompatible, with a short shelf-life and designed for a specific project purpose. Assessments and planning frameworks are also often linked to the specific technical interests and mandates of organisations and may focus on particular risks (typically natural disaster risks) for particular audiences. Territorial or mandate competition between international actors may also pose a significant barrier to developing a shared analysis of risk. Collectively, this adds up to an incoherent and piecemeal understanding of risk.

Developing analytical tools and generating accessible data is a necessary but not sufficient condition for risk informed decision-making. Indeed it is the processes around developing a shared analysis of risk that may be more important (OCHA, 2014). The political commitment and difficult reality of achieving a shared analysis of risk and priorities for risk management from which the full range of domestic and international actors could align their investments has yet to be seriously addressed.

There are several multi-stakeholder frameworks and approaches that marshal existing risk assessments to develop a shared analysis of risk and priorities for reduction, preparedness and transfer. These could potentially help to situate priorities identified within the specialised analysis of risk and contingent sovereign liabilities undertaken by governments and their technical partners and risk-transfer market assessments within a more accessible understanding of risk, which may in turn help to facilitate complementary investments and coordination.

The G20/OECD Methodological Framework for Disaster Risk Assessment and Risk Financing provides practical guidance for government-led risk assessment processes, including the need for multi-actor participation, transparency and communication of risk assessment results, all of which would considerably advance a country-level shared analysis of risk (OECD, 2013).

The Inter-Agency Standing Committee (IASC) Common Framework for Preparedness will be trialled in 2014 and may provide a model for establishing inclusive risk assessment and prioritisation processes at country level, which bring together humanitarian and development actors, including actors concerned with natural disaster and political and security risks (IASC, 2013). The Common Framework for Preparedness may be particularly well suited to contexts in which government-led risk management processes are not feasible or are not 
well developed and could help to establish the practice of regular inclusive dialogue around risk management.

The OECD's resilient systems analysis approach may also provide a galvanising framework to engage multiple actors in a common risk analysis (Box 3.4)

Box 3.4: A resilient systems analysis in the Democratic Republic of Congo (DRC)

\begin{abstract}
Eastern DRC has a complex and fluctuating risk landscape, combined with a high level of uncertainty about future events. The population need to cope with multiple shocks of diverse nature and intensity, including conflicts, illnesses and lack of employment opportunities. Each of these shocks impacts on household livelihoods systems.

How can the resilience of the population be strengthened in areas affected by multiple forms of conflict? How can humanitarian, transition and development programs support households so that they have the necessary resources and capacities to absorb, adapt and transform in the face of future shocks, when features and consequences are often still unknown?

Experts in risks, systems and livelihoods from the government, the private sector, the NGOs, the United Nations and donors worked together for two days in Goma in April 2014 to:

- Describe the concepts linked with resilience, such as risks, shocks, stressors, livelihoods and capacities.

- Share a common vision of the main risks and their impact on livelihoods assets, for host families, internally displaced people and returnees from North Kivu, South Kivu and Oriental Province over the next three years.

- Draw a roadmap to strengthen resilience and inform programming.

- Explore how they can coordinate with other key stakeholders in order to strengthen resilience in a coherent manner.
\end{abstract}

Source: OECD/UNICEF 2014

\title{
3.3 Institutional challenges
}

There is a distinct gap between the high-level, political commitments to risk financing from donor governments and the extent to which donors are actually putting their money behind risk financing. Several donors noted that while their institutions acknowledge the importance of risk financing as part of an effective risk management approach, they do not foresee a substantial increase in the volumes of funds they allocate in the next few years.

There are many practical reasons for this, not least that the challenges to scaling up risk financing are often more profound than a lack of donor funding. In addition, the role of donor financing should be catalytic; the volumes of funds required should not in theory be very large - far larger volumes for example may be required for complementary investments in risk reduction and the development of social safety net infrastructure. Nevertheless, risk financing is a challenging prospect for donors, with no obvious thematic home within their current institutional configuration and a range of potentially 'risky' attributes.

At the level of implementation, risk financing is highly specialised and complex. This complexity is a deterrent to practical engagement from actors who could be potentially useful donors, implementers, innovators and advocates. There are often misunderstandings around the qualities and potential applications of risk financing among non-specialists. Programme staff developing projects at country-level may not be aware of risk financing as a programming option. 
Risk financing is difficult to get right, the risk of failure is significant and return on investment is uncertain. Despite the compelling theoretical case for risk financing, in practice it is often a risky investment with uncertain outcomes. Moreover, there is often little evidence to justify the impact of investments. Engaging in risk financing is not for the fainthearted or risk averse.

It is worth noting that the initial financial backing for many micro-insurance initiatives came from private foundations - most prominently Bill \& Melinda Gates Foundation and The Rockefeller Foundation but also foundations linked to companies with experience and potentially a relevant business interest, including Swiss Re, Munich Re, Zurich Insurance and Swiss agribusiness Syngenta. This may be indicative of their greater level of comfort with risky investments and with working with private sector actors and business approaches.

OECD donors have exhibited a cautious approach to supporting risk financing so far - either supporting relatively safe technical programmes in multilateral institutions or funding projects at one remove, that is, contributing to initiatives that identify and finance more experimental third-party projects.

A handful of donors are gradually building their internal capacity and are likely to increasingly engage on policy-level issues. However, not every donor should engage directly with risk financing. It may be equally important to support complementary investments in an integrated risk management strategy, notably in risk assessment, risk reduction and preparedness.

Risk financing is often disbursed across multiple thematic and technical teams. Donor engagement with micro-insurance, for example, is spread on average across four separate departments (Marquaz and Chassin, 2012). This disbursement of effort across teams is likely to mean incoherence in programme objectives, which may not always be complementary. Agriculture specialists may approach agricultural insurance with a view to increasing small-holder productivity and economic growth; governance specialists with the intention of protecting governments against fiscal shocks; private sector growth specialists with the intention of promoting growth in domestic insurance markets; humanitarians with a view to accelerating the speed of response, reducing the post-disaster financing gap and increasing local ownership of response. There is a risk that fragmentation across technical units and departments could prove to be an impediment to the effective coordination of investments, learning and identifying programming synergies.

Developing common planning frameworks can help to encourage regular dialogue and coordination across disparate technical teams. The European Commission, for example, has developed a seven-year Action Plan for Resilience in Crisis Prone Countries, which articulates the rationale, priorities, actions and timeframes for implementation as well as expected outputs (EU, 2013). Departments across the Commission have mobilised around this action plan to debate and coordinate their activities. Other donors, including Switzerland, convene informal internal thematic networks including on risk, which provide opportunities for cross-departmental dialogue.

Risk-financing solutions are likely to be the product of networks of actors. In the case of donors, there are internal networks of actors as well as external networks. The role of donors within these networks is essentially catalytic, providing seed financing to enable innovation and to subsidise public goods. But the influence of donors is also potentially important. So while donors should not necessarily expect to become technical experts, they need to know enough to pose questions and to represent the interests of others particularly vulnerable populations.

Investing in partnerships with a high level of trust, and the confidence and flexibility to have frank and critical discussions, is extremely important. Donors already engaged in this field 
noted that they feel as if it is still 'early days' for them. They have typically developed partnerships over several years and rely heavily on these partners for technical guidance. There may be a need for donors to develop informal communities of practice, including networks of experts who they can draw on, to supplement their internal expertise.

There may be a need to adapt internal procedures. Donors and implementers may need to convince their institutions to adjust internal procedures and norms in order to accommodate working with new partners and new programming tools.

Establishing high-level policy commitments to risk financing, and identifying influential internal champions, can help to facilitate the internal change necessary to engage with new tools and approaches. For example, WFP's board approved the use of sovereign and micro risk insurance as official tools within the organisation's programming repertoire in its latest strategic plan. This has enabled changes in WFP's financial framework and the development of institutional mechanisms that allow WFP to engage directly in developing insurance-based products and services.

Chains of accountability may be weakened through multiple tiers of partners and attribution of results can become extremely difficult. Demonstrating results may be particularly challenging and monitoring and evaluation metrics have tended to focus on outputs rather than outcomes, which may be difficult to attribute and difficult to measure within the lifetime of an intervention. This is despite the fact that the viability of financial products is not necessarily synonymous with cost-effectiveness, nor with access for the most vulnerable.

As donors and implementers increasingly look towards achieving scale, monitoring the appropriateness, effectiveness and impact of these investments - and being prepared to adjust them accordingly - is of increased importance. If funds fail to reach target actors, or if interventions are unreasonably expensive and disproportionately benefit private sector actors, there could be a loss of confidence in risk transfer mechanisms.

Investing in developing mutually acceptable results frameworks from the outset, and agreeing a commitment to continuous learning and adaptation (Box 3.5), will also help to alleviate internal donor concerns about effectiveness, accountability and impact, and should help contribute to improved programming outcomes and sharing of lessons. Designing a framework that is acceptable to the full range of actors involved may require considerable effort and time.

Investing in public goods may not be appealing to donors. Implementing organisations noted that donor support could be most beneficial by investing in public goods, notably the provision of risk data and support to risk-transfer market development (including technical capacity-building, regulatory reform and consumer education and protection).

Some donors have demonstrated a keen interest in financing public goods. The Netherlands Space Office and Ministry of Foreign Affairs, for example, have supported the Geodata for Agriculture and Water (G4AW) Facility - an initiative that will provide at least three million farmers, in up to 15 developing countries, with satellite information via mobile phone. The project will also facilitate the development of financial and other related products that could allow food producers to make the right decisions in sustaining and increasing their production and livelihoods.

However, the appetite and incentives for donors to finance public goods are not yet clear and the difficulty in attributing results may deter donors who are concerned with demonstrating results on their investments. 
Box 3.5: The evolution of regional risk pools - continuous learning and adaptation

Small island states may be particularly vulnerable to the financial impact of disasters, often highly exposed to natural hazards, with small fiscal revenues and reserves and subject to high disaster losses relative to their gross domestic product (GDP). ${ }^{7}$ They may also be disadvantaged when trying to access market-based, risk-transfer options with high transaction costs relative to the size of insurance premiums sought. Some may also be highly indebted, limiting their access to credit.

Heads of government from the Caribbean Community (CARICOM) identified the need for catastrophe risk insurance as a priority in the wake of Hurricane Ivan in 2004 and requested assistance from the World Bank to develop a risk-transfer programme to alleviate liquidity problems in the aftermath of disasters.

The world's first multi-country, multi-peril, pooled catastrophe risk-insurance facility, the Caribbean Catastrophe Risk Insurance Facility (CCRIF), was created in 2007 with technical support from the World Bank and grant funding from Japan. A multi-donor trust fund, which received contributions of USD 67.4 million, financed start-up costs and capitalised the pool. ${ }^{8}$

Annual subscriptions are retained as reserves in the pool, with a proportion transferred to international markets through the purchase of commercial reinsurance. The collective purchasing power of the pool, together with its diversified portfolio of risk, has enabled substantial cost savings. Members pay approximately half what they would if negotiating directly with commercial reinsurers (Swiss Re, 2011).

Payouts are calculated objectively based on modelled losses and monitored against United States Geological Survey (USGS) earthquake location data National Oceanic and Atmospheric Administration (NOAA) storm data. Payments are typically received within two weeks. A total of USD 32.2 million was paid out between 2007 and 2013.

The original purpose of the CCRIF was to enable CARICOM member states to access disaster insurance at affordable rates. The CCRIF has been highly successful in meeting the objectives set at the design stage and its outcomes were duly rated as 'highly satisfactory' in the World Bank's project completion report (World Bank, 2013c) and an independent review commissioned by DFID and CIDA rated the CCRIF 'very good' for relevance and sustainability (Dlugolecki, Kalra and Mechler, 2013).

The same independent review, however, flagged concerns about a lack of clarity as to how payments had been used by governments and whether it could be confirmed that liquidity problems had been alleviated. ${ }^{9}$ Influencing the targeting and disbursement of funds was not, however, part of the ambition of the donor-funded project to establish the CCRIF. Monitoring and evaluation have also been noted as being problematic, with the World Bank's project financed by the multi-donor trust fund monitored against a results framework emphasising outputs rather than outcomes and which centred around the establishment of CCRIF with indicators based on fees and insurance purchase and its claims paying capacity (World Bank, 2013c). ${ }^{10}$

The experiences and lessons learned from the CCRIF have influenced the design of the subsequent ARC instrument, which includes a much stronger focus on accountability and outcomes for at-risk populations. Access to funds is contingent on approval of operations plans by the ARC Board's Peer Review Mechanism and payouts will be audited to confirm funds were spent as agreed. Major donors to the facility, 'Class A' member donors, have signed up to remain members for twenty years and will remain involved in key governance decisions.

The timeframe for establishing viable risk-financing strategies and mechanisms may be considerably longer than typical programming cycles. Engaging in risk financing is a long-term responsibility. Developing and then dropping potentially viable projects can have long-term negative impacts on confidence in risk financing among those it should benefit. It may take upwards of a decade for micro-insurance schemes to become sustainable. However, implementing organisations and reinsurers have pointed to a lack of continuity in donor funding as one reason why micro-insurance pilots fail to reach scale. 
The development of social safety nets gives a good indication as to the levels and length of donor engagement that may be required to achieve sustainable risk financing (Box 3.6). Notably, donors supporting the development of the African Risk Capacity have committed to remain engaged in the governance of the facility for 20 years (Box 3.5).

\section{Box 3.6: Commitment and compromise in Ethiopia's Productive Safety Net Programme}

(PSNP)

The evolution of technical tools and political commitment to social safety nets in low-income countries may have many lessons for the development of risk financing. Ethiopia's PSNP is a much-cited example of what it is possible to achieve when ambition, political commitment, technical possibilities and resources align. But realising the initiative required leadership, commitment and compromise, as well as continuous learning and adaptation.

Common purpose. By the early 2000s, after 20 years of emergency appeals and food assistance, the Ethiopian government, international donors and implementing agencies had converged on a common view that something had to change. Assistance typically arrived too late to protect against asset depletion and livelihood deterioration and could no longer be considered an acceptable response to chronic long-term food insecurity. New approaches to addressing chronic food insecurity were proving increasingly effective - including providing cash transfers and cash-for-work.

In 2003, following a particularly bad year that saw 14 million people require external assistance, the government proposed a new approach that included resettlement, support to household production and safety nets for the most vulnerable.

The real drive for the creation of a national social safety-net programme was from the government of Ethiopia which was committed to reducing food aid dependency, seen as a domestic political liability and damaging to Ethiopia's international reputation. Among international actors there were also strong champions for a safety-net approach and powerful incentives for fatigued donors to move on from costly emergency relief.

Building consensus. Initial donor support for a shift from a relief-oriented to a productive and development-oriented safety net was strong. But this initial consensus was threatened by the government's subsequent decision to bypass piloting and implement instead at scale from the outset. The overriding commitment to progress from the current modus operandi prevailed and through a process of "political horse-trading, brinkmanship and backroom bargaining" compromise on the form of the PSNP was brokered (the IDLgroup, 2008).

Conflict and disagreement between donors was not uncommon in the early stages of development of the PSNP. Donor commitment and coordination was effectively managed, however, through the creation of a donor coordination team that facilitated dialogue and promoted practical harmonisation of approaches. Donors have aligned financial reporting systems, agreed a framework and principles for coordinating with government and jointly contributed to monitoring and implementation review (the IDLgroup, 2008). By 2012, the PSNP had ten international partners benefitting from early investments in coordination and harmonised procedures: Canada, Denmark, the European Commission, Ireland, Netherlands, Sweden, the United Kingdom, the United States, WFP and the World Bank.

Commitment to learning and innovation. In starting at scale from the outset, the PSNP has always been a living experiment and PSNP partners continue to experiment and adapt to emergent problems. Monitoring and evaluation plays an important role in this process providing feedback into programme design and capacity building (the IDLgroup, 2008). The PSNP has made an important contribution to reversing the upward trend in food security - though this is partially offset by population growth and the impacts of food price shocks in 2008 (World Bank, 2011). The PSNP has continued to adapt to challenges with, for example, the addition of a contingency financing mechanism and experimentation with a parametric insurance policy to provide risk financing. ${ }^{11}$ 


\section{NOTES}

${ }^{1}$ The US government has recently for example committed to make government-held data more accessible in order to fuel innovation and adaptation under the White House Climate Data Initiative http://www.whitehouse.gov/blog/2014/03/19/climate-data-initiative-launches-strong-public-and-privatesector-commitments

${ }^{2}$ UN OCHA notes that agreeing triggers for humanitarian action in the Horn of Africa, while accepted in principle, has proved politically difficult to achieve in practice (OCHA, 2014).

${ }^{3} \mathrm{UN}$ OCHA has proposed alternate approaches to quantifying UN coordinated appeal requirements, which rely not on the sum of the cost of projects, but on methods of calculating theoretical response costs. OCHA is currently investigating potential methods.

${ }^{4}$ Lloyds (2010) contend that at the time of writing, the consensus was that the poorest $10-15 \%$ may not be able to access commercial insurance, but that this may change as governments target this group, citing the example of Georgia where the government paid the health insurance premiums of the poorest $25 \%$ of the population.

${ }^{5}$ For example, the donor-funded review of the CCRIF queried the seemingly low return (USD 32 million) on the donor and investor outlay of USD 190 million (Dlugolecki, Kalra and Mechler, 2013)

${ }^{6}$ See http://go.worldbank.org/OIYHJGV280

${ }^{7}$ For example, Grenada suffered direct losses from hurricane Ivan in 2004 equivalent to $203 \%$ of its annual GDP (Ghesquiere and Mahul, 2010)

${ }^{8}$ Donors were Bermuda, Canada, the Caribbean Development Bank, the European Commission, France, the International Bank for Reconstruction and Development, Ireland and the United Kingdom.

${ }^{9}$ Dlugolecki, Kalra and Mechler (2013) note that: "Information on the use of CCRIF payouts is sketchy and there is a lack of a reporting process, making it difficult to confirm to what extent liquidity problems were overcome. Payouts are reported to have been used for infrastructure repair, clean-up and recovery, but also for less urgent purposes such as upgrading weather monitoring facilities."

${ }^{10}$ It is worth noting that during the lifetime of the project, many donors developed much stronger requirements for demonstrating results such that their expectations at the end of the implementation period were likely much higher than at the outset. The success of the CCRIF and the desire to replicate the model elsewhere also contributed to a higher demand for evidence and lessons than perhaps could have been envisaged at project design phase.

${ }^{11}$ Hobson (2012) for example describes how the risk financing mechanism enabled a rapid scale up of assistance during the 2011 food security crisis https://blogs.worldbank.org/developmenttalk/protecting-the-vulnerable-during-crisis-and-disaster-partii-ethiopia-s-productive-safety-net-progra 


\section{Investment principles and priorities for donors}

Drawing on the experiences of donors and implementing organisations already working in the field, the following priorities, principles and practices constitute a preliminary attempt to identify guidance for donors looking to engage and further develop risk financing and risk transfer as part of their programming.

\section{Comparative advantage}

Donors vary hugely in their capacity, resources, structures and policy priorities. In order to engage in the complex world of risk financing, donors should understand, play to, and refine their existing comparative advantages.

\section{Identify your level of engagement}

There are a range of potential levels of engagement that donors may select, according to their resources, risk-taking culture, capacity and interest. Donors may opt to fully immerse themselves in risk financing, and engage actively at the policy and technical level. But not every donor needs to or indeed ought to play a leading role. In fact a division of labour among donors in support of a range of complementary investments and partnerships might be more desirable (Figure 4.1).

Figure 4.1: Potential levels of donor investment and engagement in risk financing and risk transfer
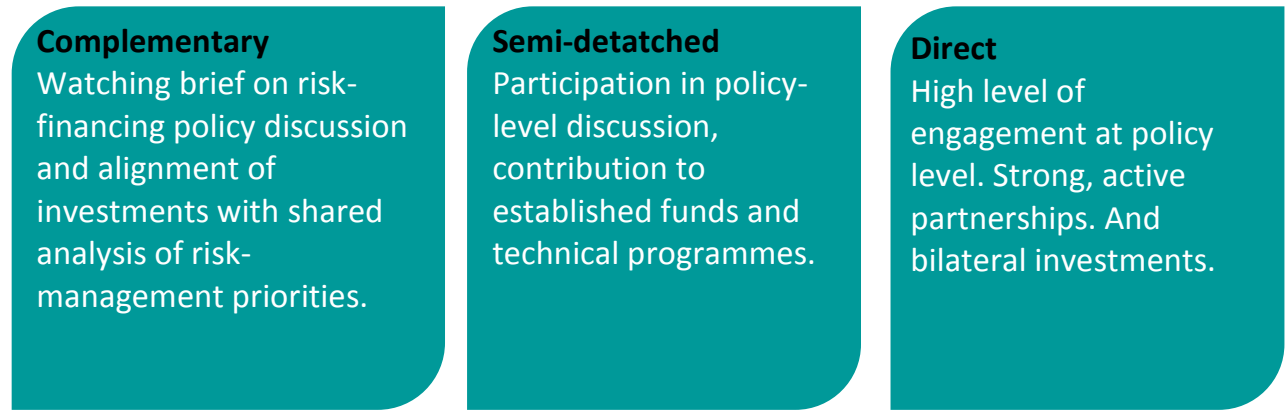

\section{Enabling investments/public goods}

(e.g. data on risk, regulatory reform and consumer education)

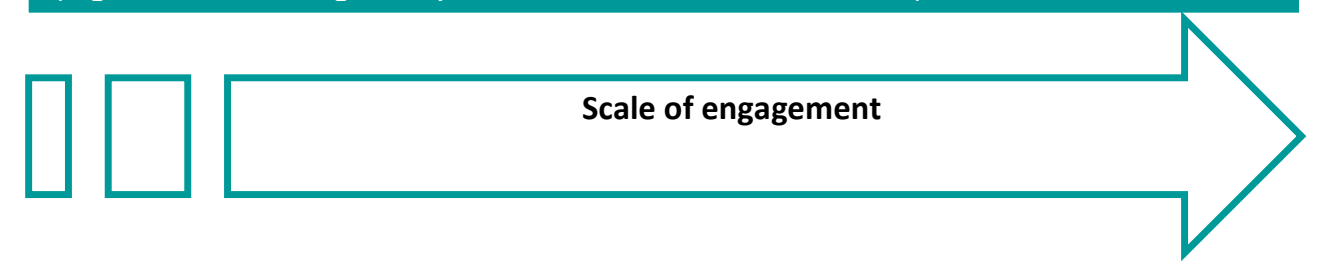

There may be a sliding scale of engagement and investment options, ranging from:

- direct engagement including bilateral support with a high level of involvement in design and monitoring of interventions,

- the cultivation of strategic partnerships and active engagement at the global policy level, 
- a more semi-detached involvement including financial contributions to established funds and programmes, and

- a risk financing aware approach that involves aligning risk management, development and humanitarian investments to complement and support risk-financing initiatives undertaken by others.

Cutting across these levels of direct engagement, there is a strong programmatic rationale for investing in complementary public goods to strengthen the enabling environment for risk financing and risk transfer.

In practice, donors may want to engage in one or a combination of these modes or levels of engagement.

\section{Adapt internal ways of working}

Donors may need to adapt their modus operandi to accommodate new partnerships and programming approaches. They may need to invest in developing internal capacity, including building awareness of risk financing as a programming option among staff at recipient-country level. They may also need to develop ways of coordinating and collaborating across disparate internal technical teams. More flexible approaches to programme monitoring and accountability which may need to incorporate several tiers of partners including private sector actors - may also need to be developed.

Establishing high-level policy commitments and supporting institutional 'champions' has helped some organisations to manage internal scepticism and resistance.

\section{Catalytic investment}

The private sector, governments and citizens of developing countries will ultimately bear the financial responsibility for preparedness against risk. Actors from the private sector and technical specialists in multilateral institutions and NGOs will most likely develop technical solutions.

Donors have particular comparative advantages - including resources that can be directed to support the public interest (rather than profit) and political influence - which can serve catalytic functions, drawing in investment from private and public sector actors and enabling others to develop and deliver risk-financing solutions.

\section{Support innovation, experimentation and learning}

Scaling-up risk financing is not a simple matter of adding more money to existing solutions. New technology, products, approaches and partnerships will be needed to address existing challenges in affordability and coverage, and to adapt to emergent risks.

Donors should continue to act as 'first movers' in funding the development and start-up costs of experimental approaches and initiatives in untested environments that might be considered too costly or risky for private sector investors, at least in the initial stages.

Donors can also ensure that partners commit to learning and openness in communicating lessons and experiences to stimulate further innovation and adaptation among the wider riskfinancing community. 


\section{Invest in public goods}

Without investments to build more enabling environments for risk financing and risk transfer, the initiatives donors currently support risk becoming islands of dubious sustainability in otherwise unpromising environments. While results may be difficult to attribute, public goods may represent donors' most important contribution to the scaling up and sustainability of risk financing.

The most frequently cited public goods that could benefit the development of risk-transfer markets, demand for risk-financing products and approaches and motivate better self-protection is the provision of data on risk and support to markets, including: technical capacity building; regulatory reform; and consumer education and protection.

\section{Promote demand and political support for risk financing}

Support for risk financing at the political level in developing countries is a critical precondition for developing sovereign risk-financing strategies and enabling the development of domestic risktransfer markets. Donors can continue to build on the current high profile of risk financing at the international level by supporting the inclusion of risk management including risk financing in commitments made in the 2015 Sustainable Development Goals, the successor arrangements for the Hyogo Framework for Action and, in 2016, at the World Humanitarian Summit. Donors can also help to facilitate south-south learning and dialogue on risk-financing experiences.

\section{Collective approaches}

Effective management of risk is the work of many actors across the public and private sector and civil society. Donors often have broad networks of partners and influence and can play an important role in influencing incentives and creating opportunities for actors to connect and work more effectively towards collective approaches to managing risk.

\section{Support a shared analysis of risk}

The absence of a comprehensive shared analysis of risk is an impediment to achieving an efficient collective response. Resources and capacity are part of the problem but the ways in which international actors approach risk assessment, including the influence of technical siloes, inter-agency politics, cultural difference and competition also represent a significant challenge to developing a shared analysis behind which multiple actors could align their efforts.

As new frameworks to foster processes of common analysis and prioritisation are tested including the IASC's framework for emergency preparedness and the OECD's resilient systems analysis - donors should observe closely and identify opportunities to embed practices of shared analysis and planning, including where necessary, creating incentives for partners who may be disinclined to share information and coordinate to do so.

\section{Promote co-operation and coordination and facilitate partnerships}

Donors can play an important role as match-makers and facilitators, creating opportunities and incentives for public, private and civil society actors to connect and develop partnerships. 


\section{Complexity}

Risk financing is straightforward in theory, but extremely complex in practice. There is very little best-practice to draw from - initiatives are more typically 'learning while doing'. Influencing behaviour and the functioning of markets are notoriously complex prospects under any circumstances. Both simultaneous and sequenced interventions at multiple points may be necessary. Moreover, the risks against which we are seeking to develop financial protection are often dynamic and, in the context of a changing climate, less predictable than current actuarial models might currently consider. Accepting complexity and uncertainty comes with the territory.

\section{Accept working with uncertainty and complexity}

Donors and their partners should be clear about their objectives but be open to flexibility and adaptation based on a commitment to continuous learning throughout the lifetime of a project. In addition, actors working in risk financing should accept that no one actor will have all of the answers; collaborations across networks are more likely to deliver results.

\section{Establish realistic expectations}

Risk financing may be a worthwhile long-term investment but the process is unlikely to be straightforward. Initiatives may require many years of support, some may fail and outcomes may be difficult to attribute. Donors should be realistic in their expectations about outcomes. It will almost certainly not be the case, for example, that investments in risk financing, even if highly successful, will lead to a neat tailing off of demand for humanitarian financing.

Donors also need to be realistic about the difficulties in applying standard planning frameworks, results and value for money metrics to risk-financing programmes.

\section{Caution}

Risk financing is part of the solution to managing risk more effectively but it does not always work everywhere. Donors should be alert to the potential limits and draw-backs of risk financing and develop their own 'layered' approaches.

\section{Maintain a balanced approach}

Risk financing should be part of a comprehensive approach, which includes risk reduction and preparedness. Risk financing and risk-transfer mechanisms do not apply to all risks or in all contexts. In addition, while risk financing makes good sense in theory, the real value and outcomes for vulnerable people in developing countries are not yet well understood. In light of this limited applicability and uncertainty of outcomes, donors would do well to hedge their bets and to pursue investments in risk financing as a strategy against which they might expect longterm returns but at the same time continue to invest in approaches that have more reliable outcomes for at-risk populations in the short-term, such as social safety nets and humanitarian cash transfer programmes as well as disaster risk reduction.

\section{Ensure investments are inclusive and benefit the most vulnerable}

The interests of the private sector and actors working at sovereign level will not always coincide with the interests of the most vulnerable. Donors should influence their partners and advocate in networks to ensure that products and initiatives take into account not just technical feasibility, client requirements and profit returns but also include the needs of the most vulnerable at design stage and that they are monitored against this. 


\section{Be alert to downside risks}

Risk financing and risk transfer are not without potential risks and unintended consequences. There is typically little pre-existing demand for insurance in developing countries and as insurance industry adage goes 'insurance is sold, not bought'. In this case, international development actors should be sure they are confident that the product they are selling has real value for poor people and cash-strapped governments since there are opportunity costs involved in purchasing insurance. Failure to scale up insurance pilots may damage public confidence and future demand for insurance. There is a risk that heavy reliance on international reinsurance in many donor-funded insurance projects could crowd out the development of local insurance markets. In short, donors and their partners should proceed with caution and remain alert to potential negative and unintended consequences and be prepared to rethink and adapt. 


\section{Conclusion}

For those immersed in the field of risk financing and risk transfer, the potential and limitations of risk financing and risk transfer in developing countries are relatively clear, but for many joining the debate more recently, it may seem an arcane and at times forbidding and exclusive area. This report seeks to provide an accessible introduction, flagging in particular some of the challenges and limits of risk financing and risk transfer for the un-initiated.

Risk financing and risk transfer are well established components of risk management in developed countries and increasingly, innovations and donor-financed initiatives are extending opportunities to better prepare for the financial cost of risk in developing countries. Many donors are already seeking to learn and adapt their internal capacity, partnerships and programming repertoire to encompass risk financing and risk transfer as part of a comprehensive approach to managing risk.

As the number and diversity of actors interested in engaging and aligning with risk financing continues to grow, a more inclusive approach to sharing experiences and lessons learned may prove beneficial to enabling increased and better informed engagement and support. Annex 1. Sovereign risk-financing at multilateral development banks 


\section{Annex 1. Sovereign risk-financing at multilateral development banks}

\begin{tabular}{|c|c|c|c|}
\hline & World Bank & Asian Development Bank & $\begin{array}{l}\text { Inter-American Development } \\
\text { Bank }\end{array}$ \\
\hline $\begin{array}{l}\text { Technical assistance and } \\
\text { intermediation support services }\end{array}$ & $\begin{array}{l}\text { Fiscal impact studies } \\
\text { Ex-ante budget planning } \\
\text { Technical assistance and } \\
\text { intermediation services to design } \\
\text { and develop: catastrophe bonds; } \\
\text { regional sovereign insurance } \\
\text { pools; national (regional) insurance } \\
\text { or reinsurance pools that facilitate } \\
\text { development of domestic (regional) } \\
\text { property catastrophe insurance } \\
\text { markets; specialised risk transfer } \\
\text { vehicles dedicated to the provision of } \\
\text { property catastrophe insurance for } \\
\text { public assets; index-based agricultural } \\
\text { insurance programmes; traditional } \\
\text { indemnity-based agricultural } \\
\text { insurance programmes; and } \\
\text { agricultural insurance pools. }\end{array}$ & $\begin{array}{l}\text { Technical assistance to develop } \\
\text { pilot projects including: } \\
\text { A public-private earthquake } \\
\text { insurance entity in the Philippines } \\
\text { covering middle class and } \\
\text { medium-sized enterprise property } \\
\text { owners; the development of city } \\
\text { level disaster risk financing options } \\
\text { and related financial literacy in } \\
\text { Indonesia, the Philippines, and } \\
\text { Viet Nam; the development of } \\
\text { public and private disaster risk } \\
\text { financing capacity in Bangladesh; } \\
\text { and several pilot index-based crop } \\
\text { insurance schemes in } \\
\text { Bangladesh, Cambodia, and Viet } \\
\text { Nam. } \\
\text { Note that the ADB recently } \\
\text { announced its intention to develop } \\
\text { an approach paper to rationalise } \\
\text { its approach to supporting disaster } \\
\text { risk financing and insurance. }\end{array}$ & $\begin{array}{l}\text { Strategic country risk evaluations } \\
\text { including probabilistic assessment } \\
\text { of risk identifying geographic areas } \\
\text { and sectors at risk, probable } \\
\text { maximum losses associated with } \\
\text { catastrophic events and their } \\
\text { economic impacts. } \\
\text { Fiscal feasibility studies } \\
\text { Design of financing mechanisms } \\
\text { (budgetary reallocations, reserve } \\
\text { funds, etc.). } \\
\text { Technical assistance to design, } \\
\text { structure and sale of catastrophe } \\
\text { bonds. }\end{array}$ \\
\hline
\end{tabular}




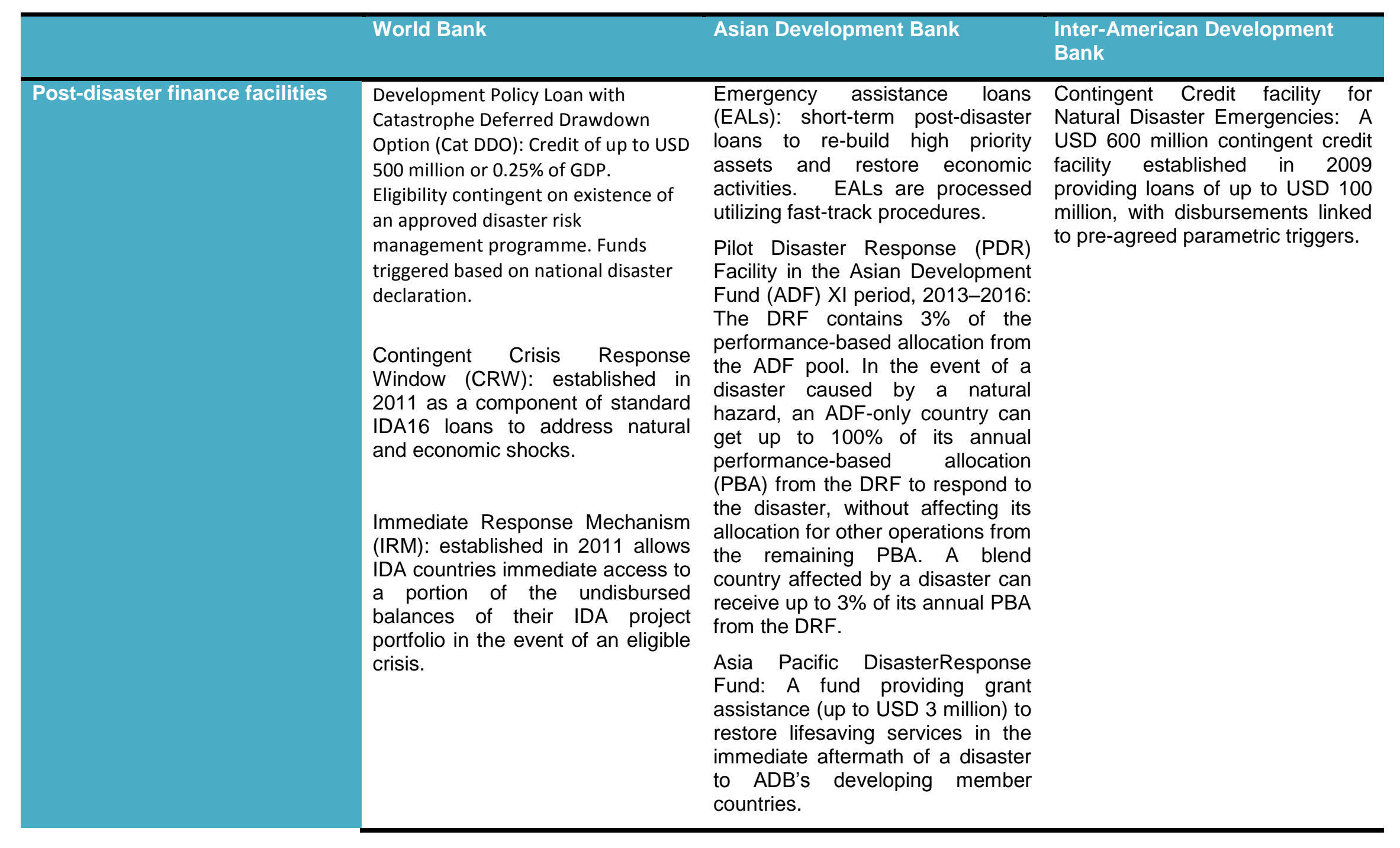




\begin{tabular}{|c|c|c|}
\hline & Asian Development Bank & $\begin{array}{l}\text { Inter-American Development } \\
\text { Bank }\end{array}$ \\
\hline $\begin{array}{l}\text { Other disaster risk financing } \\
\text { related funding mechanisms }\end{array}$ & 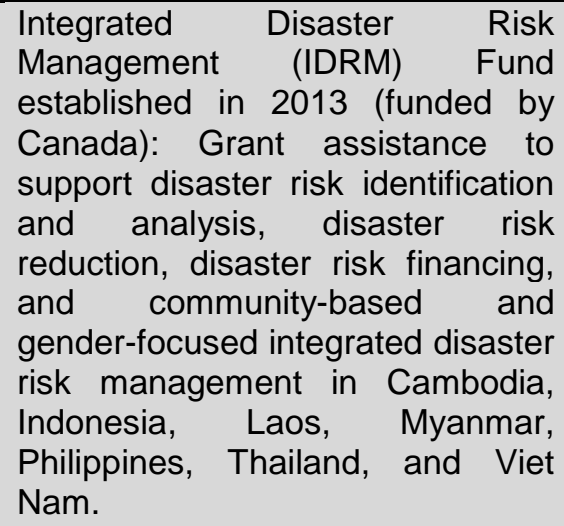 & \\
\hline
\end{tabular}

Source: Asian Development Bank, 2013b and 2014; World Bank, 2012d 


\section{BIBLIOGRAPHY}

Asian Development Bank (2013a) Investing in Resilience, Ensuring a Disaster-Resistant Future, Asian Development Bank. www.adb.org/sites/default/files/pub/2013/investing-in-resilience.pdf

Asian Development Bank (2013b) The Integrated Disaster Risk Management Fund, Asian Development Bank www.adb.org/documents/integrated-disaster-risk-management-fund

Asian Development Bank (2014) Operational plan for integrated disaster risk management 20142020, Asian Development Bank www.adb.org/sites/default/files/integrated-disaster-riskmanagement-operational-plan.pdf

Bateman, M. \& Chang, H. (2012) Microfinance and the Illusion of Development: From Hubris to Nemesis in Thirty Years, World Economic Review Vol 1: 13-36, 2012. http://wer.worldeconomicsassociation.org/files/WER-Vol1-No1-Article2-Bateman-and-Changv2.pdf

Becerra, O., Cavallo, E. and Noy, I (2012), Foreign Aid in the Aftermath of Large Natural Distasters, IDB Working Paper 333. www.iadb.org/intal/intalcdi/PE/2012/10593.pdf

Brown, T., Gibson, S. and Ashley, S. (2007) Building consensus for social protection: Insights from Ethiopia's Productive Safety Net Programme (PSNP), The IDL Group www.theidlgroup.com/documents/thelDLgroupPSNPconsensusbuildingfinal.pdf

Churchill, C. and Matul, M. (Eds) (2012) Protecting the poor: A microinsurance compendium, Volume II, International Labour Organization. www.ilo.org/wcmsp5/groups/public/---dgreports/--dcomm/---publ/documents/publication/wcms 175786.pdf

Cull, R., Ehrbeck, T. \& Holle, N. (2014) Financial Inclusion and Development: Recent Impact Evidence, Focus Note No. 92, April 2014, the Consultative Group to Assist the Poor. www.cgap.org/publications/financial-inclusion-and-development-recent-impact-evidence

Dlugolecki, A., Kalra, R. and Mechler, R. (2013) Caribbean Catastrophe Risk Insurance Facility (CCRIF): An independent review in 2012. Commissioned by DFID and CIDA. The TI-UP Resource Action Plan for Resilience in Crisis Prone Countries 2013-2020, Commission Staff Working Document, Brussels, 19.6.2013, SWD(2013) 227 final. http://ec.europa.eu/echo/files/policies/resilience/com 2013227 ap crisis prone countries en.p $\underline{\mathrm{df}}$

European Commission (2012) Social Protection in European Union Development Cooperation, Communication from the Commission to the European Parliament, the Council and Social Committee and the Committee of the Regions, Brussels, 20 August, 2012. http://ec.europa.eu/europeaid/what/social-protection/documents/com 2012446 en.pdf

Fuchs, A., Wolff, H., (2011) Drought and Retribution: Evidence form a large scale rainfall index insurance in Mexico, University of California at Berkeley, University of Washington. www.gwu.edu/ iiep/adaptation/docs/Wolff,\%20Drought\%20and\%20Retribution\%20Evidence\%20 from\%20a\%20large\%20scale\%20Rainfall-Indexed\%20(updated).pdf

Ghesquiere, F., and O. Mahul (2010) Financial Protection of the State Against Natural Disasters: A Primer. World Bank Policy Research Working Papers \#5429. http://elibrary.worldbank.org/doi/book/10.1596/1813-9450-5429 
Hobson, M. (2013) Protecting the vulnerable during crisis and disaster: Part II Ethiopia's Productive Safety Net Program, published in Let's talk development: A blog hosted by the World Bank's Chief $\quad$ Economist, 4013. https://blogs.worldbank.org/developmenttalk/protecting-the-vulnerable-during-crisis-and-disasterpart-ii-ethiopia-s-productive-safety-net-progra

IASC (2013) Inter-Agency Standing Committee Common Framework on Preparedness, 18 October 2013. https://docs.unocha.org/sites/dms/ROWCA/Coordination/Common Framework for Preparednes s Oct2013.pdf

Lloyd's (2010). Insurance in developing countries: Exploring opportunities in microinsurance. www.lloyds.com/ /media/Lloyds/Reports/360/360\%200ther/InsurancelnDevelopingCountries.pdf

Microinsurance Innovation Facility (2012) Protecting clients and organizations from climate risks through meso-level coverage, Emerging Insight \#: 41, 22 June, 2012. www.microinsurancefacility.org/emerging-insights/ei41

Mahul, O. (2013) Initial Market Surveys: Summary Note, Political Champions Group - Partnership for Stimulating Insurance Penetration in Lower Income Countries, Initial Market Assessment and Country Surveys World Bank. http://siteresources.worldbank.org/EXTDISASTER/Resources/8308420-

1352168039865/Political-Champions-25-Sept-insurance-summary-note-final.pdf

Marquez, P. and Chassin, L. (2012). Donors in microinsurance, Microinsurance Network Study No. 4 Microinsurance Network. www.microinsurancenetwork.org/publication/fichier/MIN Donor study 2012.pdf

Mitchell, A. (2013), Risk and Resilience: From Good Idea to Good Practice, A scoping study for the Experts Group on Risk and Resilience, OECD Development Co-operation Working Paper: WP 13/2013, France, December 2013. www.oecd.org/dac/governancedevelopment/FINAL\%20WP\%2013\%20Resilience\%20and\%20Risk.pdf

OECD, (2013) Disaster Risk Assessment and Risk Financing, A G20 / OECD methodological framework

www.preventionweb.net/files/globalplatform/5198f8ec10490Disaster Risk Assessment and Ris k Financing.pdf

Oxfam America (2014) R4 Rural Resilience Initiative Quarterly report, October-December 2013. http://www.oxfamamerica.org/static/media/files/R4-October-to-December-2013.pdf

Pénicaud, C. \& Katakam, A. (2014) State of the Industry 2013, Mobile Financial Services for the Unbanked, Groupe Speciale Mobile Association (GSMA). www.gsma.com/mobilefordevelopment/wp-content/uploads/2014/02/SOTIR 2013.pdf

von Peter, G., von Dahlen, S., Saxena, S. (2012) Unmitigated disasters? New evidence on the macroeconomic cost of natural catastrophes, Bank for International Settlements Working Papers No 394 www.bis.org/publ/work394.pdf

Swiss RE (2011) Closing the financial gap: New partnerships between the public and private sectors to finance disaster risks. www.swissre.com/rethinking/crm/Closing the financial gap.html

UNISDR (2013) From Shared Risk to Shared Value - The Business Case for Disaster Risk Reduction. Global Assessment Report on Disaster Risk Reduction, United Nations Office for Disaster Risk Reduction (UNISDR). www.preventionweb.net/english/hyogo/gar/2013/en/home/download.html 
World Bank (2011), Ethiopia - Productive Safety Nets Project (APL1). World Bank. http://documents.worldbank.org/curated/en/2011/06/14540380/ethiopia-productive-safety-netsproject-apl1

World Bank, (2012a) The Sendai Report: Managing Disaster Risks for a Resilient Future, World Bank. www.gfdrr.org/sites/gfdrr.org/files/Sendai Report 051012.pdf

World Bank, (2012b). FONDEN : Mexico's natural disaster fund -a review. World Bank. http://documents.worldbank.org/curated/en/2012/05/17291287/fonden-mexicos-natural-disasterfund-review

World Bank. (2012c) Sovereign Disaster Risk Financing, Disaster Risk Financing and Insurance Concept Note, updated $\quad$ March 2012 http://siteresources.worldbank.org/EXTDISASTER/Resources/SDRF Concept Final.pdf

World Bank, (2012d) Improving the assessment of disaster risks to strengthen financial resilience: A special joint G20 publication by the government of Mexico and the World Bank www.gfdrr.org/G20DRM

World Bank, (2012e) World Bank Group Disaster Risk Financing \& Insurance (DRFI) Business Lines, $\quad$ updated March 2012. http://siteresources.worldbank.org/EXTDISASTER/Resources/WBG DRFI Business Lines.pdf

World Bank (2012f) The World Bank 2012-2022 Social Protection Strategy, World Bank. http://siteresources.worldbank.org/SOCIALPROTECTION/Resources/280558-

1274453001167/7089867-1279223745454/7253917-1291314603217/SPL Strategy 201222 FINAL.pdf

World Bank, (2013a) World Development Report 2014: Risk and Opportunity_Managing Risk for Development, World Bank.

World Bank (2013b). Ethiopia - Using a social safety net to deliver disaster insurance to the poor: case study. World Bank. http://documents.worldbank.org/curated/en/2013/06/18142261/ethiopiausing-social-safety-net-deliver-disaster-insurance-poor-case-study

World Bank (2013c), Implementation Completion Report (ICR) Review - Caribbean Catastrophe Risk Insurance Facility. World Bank. http://Inweb90.worldbank.org/oed/oeddoclib.nsf/DocUNIDViewForJavaSearch/8525682E006860 3785257B20007CA25E?opendocument

World Bank (2014). Open Data for Resilience Field Guide. World Bank. www.gfdrr.org/sites/gfdrr.org/files/publication/OPENDRI fieldGuide WEB 0.pdf 


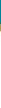

